\title{
Theory of Mind or Social Information Processing Training: Which Is the Better Way to Foster Social Adjustment?
}

\author{
Emilie Jacobs, Nathalie Nader-Grosbois \\ Psychological Sciences Research Institute: Chair Baron Frère in Specialized Education, UCLouvain, Louvain-La-Neuve, Belgium \\ Email: emilie.jacobs@uclouvain.be,nathalie.nader@uclouvain.be
}

How to cite this paper: Jacobs, E., \& Nader-Grosbois, N. (2020). Theory of Mind or Social Information Processing Training: Which Is the Better Way to Foster Social Adjustment? Psychology, 11, 1420-1453. https://doi.org/10.4236/psych.2020.119091

Received: July 31, 2020

Accepted: September 26, 2020

Published: September 29, 2020

Copyright $\odot 2020$ by author(s) and Scientific Research Publishing Inc. This work is licensed under the Creative Commons Attribution International License (CC BY 4.0).

http://creativecommons.org/licenses/by/4.0/

\begin{abstract}
Theory of Mind (ToM) and Social information processing (SIP) are key sets of social cognition skills to develop good competences in social interactions and adjustment. In children with intellectual disabilities (IDs), socio-emotional competences are deficient and impaired their social inclusion. While it is known that some ToM or SIP trainings could be effective in population with IDs, no study investigated the transfer effects between ToM and SIP and the differentiated effect of ToM and SIP trainings on social adjustment. To address these goals, 45 elementary school children with IDs were recruited. They were randomly allocated to either one of the two experimental groups (ToM or SIP group) or to the control group. Each child and his or her parents completed measures at pre- and post-test to assess cognitive abilities, ToM and SIP skills and social adjustment. Results demonstrated a transfer effect varying depending on the nature of the understanding of mental states (affective or cognitive ToM) and of social situations (positive or negative) eliciting SIP. Findings give psychoeducational guidelines for interventions that aimed at fostering socio-emotional competences in children with IDs.
\end{abstract}

\section{Keywords}

Theory of Mind, Social Information Processing, Training, Intellectual Disability, Social Competence

\section{Introduction}

Social cognition is defined as the ability to process a range of stimuli in order to assess people's behavior and engage in social interaction (Happé, Cook, \& Bird, 2017). It encompasses in particular Theory of Mind (ToM) and Social informa- 
tion processing (SIP) skills, both of which are key sets of skills for experiencing the social world positively. As a key factor for successful social inclusion in children with atypical development, it is crucial to determine how to train these skills, in an effective way? Which variable has to be targeted in a training to foster better social adjustment, even if they present diverse profiles?

ToM is defined as the ability to understand one's own and other people's mental states, to infer other people's mental states in order to predict social behavior leading to respond in socially adaptive ways (Barisnikov, Van der Linden, \& Detraux, 2002; Deneault \& Ricard, 2013; Denham et al., 2003). Mental states include desires, emotions, intentions, beliefs, false beliefs, pretense, knowledge, thinking, visual perception, and attention (Flavell, 1999). ToM is defined according to the nature of these mental states as affective or cognitive. Affective ToM corresponds to the understanding of desires and emotions, while cognitive ToM is related to the understanding of the other mental states. Children with intellectual disabilities (IDs) have been found to display delay and deficit in affective and cognitive ToM respectively, with a significant interindividual variability in their profiles depending on their individual characteristics (Jacobs, Simon, \& Nader-Grosbois, 2020). ToM abilities are part of a developmental perspective, while the SIP skills form part of a functional view. The SIP model describes a process of five steps that every person goes through in a social situation (Crick \& Dodge, 1994). The five cognitive steps of SIP are: 1) encoding and 2) interpretation of social cues, 3) goal clarification, 4) generation of responses and 5) selection of a response (Crick \& Dodge, 1994). A correct use of these steps could ensure adjusted social behaviors. The model was designed to detect which SIP steps are deficient in typically developing children displaying or at risk to display externalizing behavior disorders or antisocial behaviors (e.g. aggression or exclusion) (Dodge, 2014). However, van Nieuwenhuijzen et al. (2006) applied the model to populations with IDs, in order to explain how the risk of behavioral problems develops. Children and adolescents with IDs display difficulties in encoding (step 1) and interpretation (step 2) of social cues, especially negative ones (van Nieuwenhuijzen, Orobio de Castro, Wijnroks, Vermeer, \& Matthys, 2004; van Nieuwenhuijzen, Orobio de Castro, Wijnroks, Vermeer, \& Matthys, 2009), leading to the incorrect evaluation of possible assertive responses and hence to aggressive reactions (Leffert \& Siperstein, 1996; van Nieuwenhuijzen et al., 2009; van Nieuwenhuijzen \& Vriens, 2012). For a nuanced examination of the social cognition profiles of children with IDs, both ToM and SIP abilities need to be taken into account. In their study, Jacobs, Simon and Nader-Grosbois (2020) observed that children with IDs who displayed specific strengths in ToM and SIP abilities also had a higher developmental age and better socio-emotional skills. They emphasized specific significant links between ToM and SIP skills according to whether the social situation was described as positive (i.e. helping, prosocial) or negative (i.e. provocation, conflict, aggression, social exclusion). ToM and SIP skills share some common processes. During the inference of mental states and when processing social information, cognitive and socio-perceptive processes 
should be activated. These processes are often adversely affected in children with IDs, due to deficits in executive functions (Borella, Carretti, \& Lanfranchi, 2013; Carretti, Belacchi, \& Cornoldi, 2010; Danielsson, Henry, Messer, \& Rönnberg, 2012; Lanfranchi, Jerman, Dal Pont, Alberti, \& Vianello, 2010) and in visual discrimination of stimuli (Boot, Pel, Evenhuis, \& van der Steen, 2012; Visu-Petra, Benga, Incaş, \& Miclea, 2007). These findings underline the importance for psychoeducational interventions of considering strengths and weaknesses in ToM and SIP profiles in children with IDs. It suggests that some steps of SIP could be used to help these children understand or infer other people's mental states, and that the promotion of affective and cognitive ToM could facilitate proper use of SIP in critical social situations.

In the recent literature on interventions, a lot of studies have focused on ToM (Fernández-Sotos et al., 2019). However, only a very few of these have related to subjects displaying IDs (e.g. Jacobs, Léonard, Nader-Grosbois, Houssa, \& Mazzone, 2016; Jacobs \& Nader-Grosbois, 2020a; Lachavanne \& Barisnikov, 2013; Stewart \& Singh, 1995). These experimental studies indicate the effectiveness of ToM interventions among populations with IDs depending on the subjects' characteristics, the intervention targets and the timing, as well as on the use of specific evaluation measures, materials and techniques (for a review see Jacobs \& Nader-Grosbois, 2020a). After participating in ToM training, elementary school children with IDs show an improved understanding of affective mental states (as emotions and desires; Jacobs et al., 2016; Jacobs \& Nader-Grosbois, 2020a; Lachavanne \& Barisnikov, 2013; Stewart \& Singh, 1995) and also of cognitive mental states (e.g. belief, false beliefs, perspective taking, intentions or pretense; Jacobs et al., 2016; Jacobs \& Nader-Grosbois, 2020a; Montoya-Rodríguez \& Molina-Cobos, 2019). After training, these children are also perceived as more socially adapted by their teachers (Jacobs \& Nader-Grosbois, 2020a). Concerning SIP interventions, very few have been tested in experimental studies. Such studies have been conducted on adolescents and adults with IDs (Anderson \& Kazantzis, 2008; Cote, 2011; Crites \& Dunn, 2004; Nestler \& Goldbeck, 2011; O'Reilly et al., 2004; Vlachou \& Stavroussi, 2016), and only two have focused on elementary school children displaying IDs (Jacobs et al., 2016; Jacobs \& Nader-Grosbois, 2020b). The findings of these studies demonstrate the effectiveness of SIP training for people with IDs. After training, participants identify social problems more easily and classify situations as positive or negative more accurately (Cote, 2011; Jacobs et al., 2016; Jacobs \& Nader-Grosbois, 2020b). They also provide coherent justification of social behaviors, especially inappropriate behaviors (Jacobs \& Nader-Grosbois, 2020b). Children with IDs mainly improved their skills in dealing with negative situations or inappropriate behaviors, which is precisely the area in which they had displayed greater difficulties (Hippolyte, Iglesias, Van der Linden, \& Barisnikov, 2010; van Nieuwenhuijzen et al., 2004; van Nieuwenhuijzen et al., 2009). SIP interventions also seemed to improve social competences (Nestler \& Goldbeck, 2011) and adjustment as perceived by adults (Jacobs \& Nader-Grosbois, 2020b). Children with IDs displayed 
more positive socio-affective profiles and better emotion regulation abilities after SIP training than children who had not received training. In their interactions with peers and adults, trained children with IDs are perceived as more cooperative, autonomous, integrated, empathic and positive (Anderson \& Kazantzis, 2008; Jacobs \& Nader-Grosbois, 2020b). Parents or educators also reported fewer internalized problems (e.g. isolation, withdrawal) in trained participants (Jacobs \& Nader-Grosbois, 2020b; Nestler \& Goldbeck, 2011).

ToM and SIP interventions seem effective in populations with IDs and foster social interactions and adjustment. However, to our knowledge only two studies (Houssa, Nader-Grosbois, \& Jacobs, 2014; Jacobs et al., 2016) have investigated the differentiated effects of short-term ToM and SIP trainings or tested the potential transfer effects. Jacobs et al. (2016) conducted a single intense training session focusing on either ToM or SIP in children with IDs. The goal was to explore whether elementary school children with IDs, presenting a developmental age from 3-to 6 years, were receptive to each kind of training and to appreciate the positive clinical impact on individual ToM and SIP profiles. Compared to the control group, children who participated in the ToM session showed better abilities during the task assessing social problem-solving skills, particularly by considering the intersubjectivity between characters in fictive social situations (positive and negative). After a session of SIP training and compared to a control group, children with IDs seemed more receptive and boosted their understanding of beliefs (Jacobs et al., 2016). Houssa, Nader-Grosbois and Jacobs (2014) observed similar improvement in social problem-solving skills in typically developing preschoolers after two intensive ToM training sessions, and better understanding of beliefs after two intensive SIP training sessions (Houssa, Nader-Grosbois, \& Jacobs, 2014). Yet, these two exploratory studies showed a clinical interest to stimulate social cognition in targeting ToM or SIP processes. Observations and results emphasized the very good receptivity and motivation in preschoolers or in children with IDs, toward some supports and techniques stimulating in subgroups either their understanding of emotions and beliefs or the steps of SIP. However, these training should be implemented in more sessions during several weeks and a follow-up should be applied, in order to test the differentiated efficiency of ToM and SIP trainings and the transfer effect.

Although ToM and SIP are two distinct constructs, the different theoretical backgrounds and visions suggest that there is an underlying structure (Jacobs et al., 2020) that leads children with IDs to learn something beyond the immediate context of training (Kloo \& Perner, 2003). Various authors have underlined the role of understanding mental states (e.g. intentions, emotions or thoughts) in dealing with positive and negative social problems (Crick \& Dodge, 1994; Jacobs et al., 2020; Lemerise \& Arsenio, 2000; Lemerise, Gregory, \& Fredstrom, 2005). Recently a research demonstrated that children with IDs use affective ToM in negative situations such as hostile intentions, provocation or frustration, and cognitive ToM in positive situations when they have to help or share (Jacobs et al., 2020). 
The very specific profiles of children with IDs in terms of ToM and SIP abilities and socio-emotional skills (including social adjustment, emotion regulation and socio-affective competences) could limit their social interactions, affecting their learning and social inclusion. It creates a vicious circle for these children, who already experience daily rejection and frustration. To foster socio-emotional competences in children with IDs, training focusing on either ToM or SIP needs to be implemented in these children. By understanding affective and cognitive mental states and by processing social information correctly, children will be able to enact prosocial behaviors, interact with peers and adults adaptively and be socially included (Yeates et al., 2007). The enhancement of socio-emotional competences in children with IDs is quite important and fully in line with the inclusive education and the positive environment fostered in school settings. Concretely, two questions were examined: 1) Are ToM or SIP training programs better at fostering socio-emotional competences? 2) Could ToM training program have an impact on SIP skills, and vice-versa?

The objective of the present study was to investigate whether ToM or SIP training is better at fostering social cognition and adjustment. We aimed to identify the causal contribution of ToM and SIP to each other and to social adjustment in children with IDs. To this end, an experimental study was carried out by implementing ToM and SIP trainings in children with IDs and analyzing their specific effectiveness by comparing the results to those of a control group at preand post-test. We hypothesized that children with IDs who participated in ToM training would improve their SIP skills and vice-versa, demonstrating the existence of a transfer effect. The comparison of the effects of the two training programs allowed us to identify the program to which the children were more receptive. We also expected that both ToM and SIP trainings would foster children's social adjustment, as perceived by adults in their daily life.

\section{Method}

\subsection{Participants}

Before the recruitment of subjects began, an ethics committee of the faculty of psychology at UCLouvain approved the research procedure. Experimenters contacted specialized primary schools in French-speaking areas of Belgium to explain the goals, procedure and inclusion criteria of the study. If school directors and teachers agreed to participate, they were asked to indicate which children met the study's criteria. The parents of these children with IDs received via their teachers a consent form explaining the research goal and procedure. In return for agreeing to be involved in the study, the parents were offered a report on their child's competences based on the completion of the different measures.

In this way, 45 children ( 30 boys and 15 girls) with non-specific IDs were recruited. They had an average chronological age of 9 years $(M=109.87$ months; $\mathrm{SD}=20.94$ months), ranging from 5 to 12 years. They are elementary school children. Therefore, they experienced numbers of social interactions and learned 
about the contextually appropriate character of emotions and behaviors (Raver, 2002; Valiente, Swanson, DeLay, Fraser, \& Parker, 2020). Their average global developmental age was 5 years $(\mathrm{M}=62.67$ months; $\mathrm{SD}=13.45$ months $)$ ranging from 3 to 7 years. It matched a critical developmental period for ToM and SIP competences. These children had been diagnosed as having IDs by professionals and according to AAIDD (American Association on Intellectual and Developmental Disabilities) and DSM-V (Diagnostic and Statistical Manual of Mental Disorders) criteria. Recruitment was restricted by strict inclusion criteria. Firstly, children had to present mild to moderate IDs, in other words an intellectual quotient between 50 and 70. This criterion was verified in a cognitive assessment report drawn up by professionals. Because of their specific profile of socio-emotional competences, children with Williams' syndrome or an associated autistic spectrum disorder were also excluded. Regarding verbal abilities, children had to be able to form sentences of three to four words. Schools, teachers and parents all had to give their informed consent, as well as their approval of the video recording of training sessions. Finally, both parents and teachers agreed to complete questionnaires at pre- and post-test. The sample size was therefore restricted. Moreover, some participants $(n=16)$ left the research program while it was in progress. This dropout rate was due to one school ending its involvement for organizational reasons; the questionnaires were also regarded as too time-consuming and demanding by some parents. These reasons explained why the sample was of 45 observations.

\subsection{Measures}

\section{Cognitive measure}

\subsubsection{Wechsler Preschool and Primary Scales (WPPSI-III; Wechsler, 2004)} During the pre-test session only, four subtests of WPPSI-III were administered to the children. Two of these subscales assessed verbal cognitive abilities, namely "information" and "vocabulary" tasks. The two others, the "block design" and "matrix reasoning" subscales, evaluated non-verbal cognitive functioning. Together, these subscales indicated an approximative global developmental age for each child. The experimenters could thus verify whether the children met the study's inclusion criteria.

\section{ToM measures}

\subsubsection{ToM-Emotions Tasks (Thirion-Marissiaux \& Nader-Grosbois, 2008b)} This computerized tool (on Eprime) evaluates the comprehension of causes and consequences of four basic emotions, namely joy, sadness, anger, and fear. The tool consists of three tasks: 1) A preliminary task assesses recognition of joy, sadness, anger, and fear from facial expressions. 2) A second task measures the comprehension of the causes of these four emotions. Situations of joy, sadness, anger or fear are presented in images to the children. The beginning of each 
script is the same (a group of three children set out to have a picnic lunch). The children have to predict the protagonist's emotion depending on the rest of the story. They need to identify the emotion and justify their response. 1 point is awarded for emotion recognition and 0.5 for a coherent justification. The maximum total score is 6. 3) A third task evaluates the comprehension of consequences caused by joy, sadness, anger, and fear. Four scripts are presented to the children, in which the protagonist feels joy, anger, sadness and fear respectively. The children have to choose the protagonist's reaction from three behavioral responses illustrating socially adjusted, maladjusted or neutral behavior on different vignettes. If the child chooses the socially adjusted card, 1 point is awarded; if the maladjusted or neutral card is chosen, no points is awarded. The choice has to be justified by the child. A coherent justification scores 0.5 points. The maximum total score is 6 . The entire ToM-emotions measure is thus scored out of 12 .

Validation of the original paper version revealed a high level of inter-judge agreement (between 95\% and 98\%, with Cohen's kappa between 0.89 and 0.92 and Pearson correlation coefficient between 0.93 and 96), based on each item score as well as for each task and emotion. Factorial analysis revealed two factors relating to the two tasks assessing causes and consequences of emotions respectively (Thirion-Marissiaux \& Nader-Grosbois, 2008b). Factorial and reliability analysis of the computerized measures showed the same factors and a Cronbach's alpha of 0.57 as well as a very high test-retest stability for the two subscales (between 0.56 and 0.68 ). The analyses relating to the original paper version were conducted on 80 children with and without IDs matched for preschool developmental age, whereas the analyses of the computerized version were conducted on typically developing preschoolers. For the present study, Cronbach's alpha was 0.38 and 0.35 respectively. This low reliability could be explained by the quite small sample size and a higher variability between subjects. This finding has to be considered in interpretation of results.

\subsubsection{ToM-Beliefs Tasks (Thirion-Marissiaux \& Nader-Grosbois, 2008a)}

This measure estimates the understanding of beliefs through five popular tasks: 1) the deception skills task (Oswald \& Ollendick, 1989), assessing the ability of the child to deceive an adult by hiding a little object in his or her hands; 2) the change of representation task (J. H. Flavell, Everett, Croft, \& Flavell, 1981), in which the child has to infer what the adult sees on a specific image; 3) the appearance-reality task (J. H. Flavell, 1986), evaluating the child's capacity to distinguish appearance from reality with respect to an object whose appearance differs from its real function (e.g. a pencil that looks like a flower); 4) the unexpected content task (J. Perner, Leekam, \& Wimmer, 1987), assessing the child's ability to infer a person's false belief concerning the unexpected contents of a prototypical box, such as a Smarties box filled with pencils; and 5) the change of location task (Wimmer \& Perner, 1983), namely the well-known "Max and the transfer of chocolate" task. Each task scores 1 with a maximum score of 5. 
Reliability analysis of the ToM-beliefs tasks demonstrated a very high inter-judge agreement (between 99\% and 100\%; Cohen's kappa between 0.98 and 0.99; Pearson correlation coefficient between 0.99 and 1). A test-retest session revealed no significant difference (Thirion-Marissiaux \& Nader-Grosbois, 2008a). This analysis was conducted with typically developing preschoolers and with children with IDs (ages 6 - 15) who displayed a preschool developmental age. Cronbach's alpha for the present sample was 0.31 . This observation could be explained with the same reasons cited above: small sample size and higher inter-variability.

\subsubsection{ToM-Task Battery-French version (Hutchins, Bonazinga, Prelock, \& Taylor, 2008; Nader-Grosbois \& Houssa, 2016)}

This measure assesses the comprehension of affective, cognitive and mixed mental states through nine tasks: 1) Emotion recognition; 2) Perspective-taking; 3) Inference of desire-based emotion; 4) Inference of perception-based belief; 5) Inference of perception-based action; 6) False belief; 7) Inference of belief- and reality-based emotion and second-order emotion; 8) Message-desire discrepancy; 9) Second-order false belief. During each task, the children are asked different questions with specific purpose; a) control question to check if the child understands correctly the story (e.g. "What does Brigitte want?", "Where did Anthony put his book?"), b) prompt question to guide the child (e.g. "Where is the book now?") or c) test question that evaluates the understanding of mental states (e.g. "Where will Anthony look for his book?"). Only the answers to the test questions are counted. Each task scores 1 point, with three exceptions: emotion recognition, which scores 4 points ( 1 point for recognition of joy, sadness, fear and anger respectively); perspective-taking, which scores 2 points (since the child has to take the perspective of two protagonists); and inference of belief- and reality-based emotion and second-order emotion, which scores 2 points (1 point for recognition of emotion and 1 for recognition of second-order emotion). The maximum total score is 15 . Three subscores can be calculated to obtain an affective score (with a maximum of 6), a cognitive score (with a maximum of 6) or a mixed score (with a maximum of 3 ).

This measure was validated with children with autism spectrum disorder (ages 4.5 - 12) and revealed good internal consistency $(\alpha=0.91)$ and test-retest reliability (Hutchins, Prelock, \& Chace, 2008). The French version was validated on typically developing preschoolers (ages 3 - 6). Analysis revealed good internal consistency $(\alpha=0.75)$ and test-retest reliability $(r=0.87)$ (Nader-Grosbois \& Houssa, 2016). Cronbach's alpha for the present sample revealed good reliability $(\alpha=0.74)$.

\subsubsection{Theory of Mind Inventory-French-Version (ToMI-Vf; Houssa, Mazzone, \& Nader-Grosbois, 2014; \\ Hutchins, Prelock, \& Bonazinga, 2012)}

This questionnaire assesses parents' perceptions of their child's ToM abilities in daily life. Parents evaluate through 39 items the child's comprehension of de- 
sires, emotions, beliefs, intentions, attention, perception, thinking, pretense and knowledge. For each item, parents indicate the intensity or the frequency of the described behavior on a continuum from 0 ("Absolutely not") to 20 ("Very likely"). The maximum total score is 20 , since it is calculated as the mean of all the item scores. Three subscores can be calculated for the comprehension of cognitive mental states, socio-emotional mental states and intentions and beliefs. Validation analysis of the French version revealed good internal consistency ( $\alpha=$ $0.94)$ and test-retest reliability $(r=0.86)$ (Houssa, Mazzone, \& Nader-Grosbois, 2014). These findings coincide with those for the original version (Hutchins et al., 2012). In the present study, Cronbach's alpha was also 0.94 .

\section{SIP measure}

\subsubsection{Problem-Solving Task (RES, Barisnikov, Van Der Linden, \& Hippolyte, 2004)}

The problem-solving task estimates how children understand a protagonist's good or bad behavior in fictitious critical social situations, illustrated by 14 vignettes (9 with bad behaviors and 5 with good behaviors). It mobilizes SIP skills and evaluates children's capacity to judge a behavior as appropriate or not (judgment score), to identify target behavior with social cues (identification score), and to justify their judgment (justification score). To assess the judgment and the identification of critical behavior, the experimenter asks the child "Is this good or bad?" and "Could you say what is good or bad?" respectively. These two questions indicate whether the child has perceived and interpreted social cues well. The justification score is determined by the extent to which children base their response on the consequence for the protagonist (descriptive level: 2 points), on their social consciousness (intersubjective level: 5 points), or on reference to social rules (conventional level: 7 points). It is possible to distinguish scores relating to appropriate or inappropriate vignettes. The maximum total score is 140 : 28 for judgment, 14 for identification and 98 for justification. The validation was performed with typically developing children and children with IDs and revealed an inter-judge agreement of $98 \%$ (Hippolyte et al., 2010). For the present sample, the Cronbach's alpha was 0.87 .

\section{Socio-emotional and behavioral measures}

\subsubsection{Social Adjustment Scales for Children (EASE; Hughes, Soares-Boucaud, Hochman \& Frith, 1997)}

This questionnaire measures adults' perception of children's social adjustment. Parents estimate how frequently particular behaviors occur in daily interactions (rarely, relatively frequently or usually). Forty-six (46) of the items measure adaptive social skills (e.g. politeness, discipline or civility), and the remaining items (52) assess social behaviors related to ToM abilities (e.g. considering others' emotions, desires or beliefs). Two subscores can be calculated: one for social skills (maximum 46) and the other for ToM (maximum 52). Validation analysis was carried out on 327 preschoolers and revealed good internal consistency in 
the two subscales, with Cronbach's alphas of 0.77 and 0.79 (Hughes, Soares-Boucaud, Hochmann, \& Frith, 1997). Similarly, good reliability was obtained for the present sample, with Cronbach's alphas of 0.79 and 0.78 .

\subsubsection{Child Behavior Checklist (CBCL; Achenbach, 1991)}

This well-known questionnaire of 79 items assesses parents' perception of their child's behavioral and emotional problems. Parents indicate the frequency of the child's behaviors on a 3-point Likert scale, from "not at all" to "often". This produces, among other things, two scores for the presence of either internalizing or externalizing behaviors. Four subscales, namely "anxious/depressed", "emotionally reactive", "withdrawn" and "somatic complaints", determine the internalizing behavior score (clinical cutoff $>17$; maximum score 72), whereas the "attention problems" and "aggressive behavior" subscales are integrated to provide the externalizing behavior score (clinical cutoff $>24$; maximum score 48). These scores provide information about the sample's clinical profile and potential risk of behavioral problems. Cronbach's alpha for the different subscales is between 0.63 and 0.86 . For the present study, Cronbach's alpha was 0.85 . The template is used to format your paper and style the text. All margins, column widths, line spaces, and text fonts are prescribed; please do not alter them. You may note peculiarities. For example, the head margin in this template measures proportionately more than is customary. This measurement and others are deliberate, using specifications that anticipate your paper as one part of the entire journals, and not as an independent document. Please do not revise any of the current designations.

\subsection{Procedure}

After giving their consent, all children and their parents took part in pre- and post-test sessions. Concerning children, performance-based measures were administered in a quiet room at school, during two to three sessions of $30-45 \mathrm{mi}-$ nutes. About parents, they were systematically met once at pre- and post-test. If they wished, they could receive help from the experimenter with completing the questionnaires assessing their perception of their child's performance (i.e. ToM abilities, social adjustment, social and behavioral competences). $71 \%$ of parents requested this kind of help. This high level could be explained by the parents' low socio-economic status and educational level. Many of the items were difficult for them to understand. The parents also appreciated the opportunity to talk about the daily difficulties they faced instead of just choosing a specific response without explanation. After pre-test, children were randomly allocated to the control or one of the two experimental groups. Children of the two experimental groups attended either the "ToM program for children" (Jacobs \& Nader-Grosbois, 2018b) or the "SIP program for children" (Jacobs \& Nader-Grosbois, 2018a). The "ToM program for children" aimed to enhance the understanding of affective and cognitive mental states (for more details see Jacobs \& Nader-Grosbois, 2020a), while the "SIP program for children" was designed to foster 
appropriate social information processing and improve social problem-solving skills (for more details see Jacobs \& Nader-Grosbois, 2020b). These two programs are briefly described below and in Appendixes A, B and C. Children in the control group were placed on a waiting list and received the same training after post-test.

ToM Program for Children (Jacobs \& Nader-Grosbois, 2018a, 2020a)

The ToM program for children is based on a literature review of ToM training for children with developmental disabilities and in particular on the program developed by Howlin et al. (2011) for children with autistic spectrum disorders. The program aimed to foster comprehension of all nine mental states described by Flavell (1999), i.e. affective and cognitive mental states, to an equal extent. The sessions increased in complexity over time, and were constructed to take account of the zone of proximal development and the developmental cascade. The eight 45-minute sessions of this program took place twice a week and were run by two experimenters in subgroups of 3 to 4 children. The experimenters followed a set of instructions describing each activity, and in particular the materials and techniques to be used. The materials included games with visuals, cartoons or picture books that specifically presented characters in one or more mental states. Each session targeted affective or cognitive mental states. The sessions had the same structure: they began with a reminder of the last session; the trainers then ran 3 to 4 activities and each session was closed with the reading of a picture book. Specific techniques were chosen in accordance with the specific profiles of children with IDs and the general and specific objectives: questions targeting affective or cognitive mental states, explanations of the correct answer using key concepts (e.g., "You feel happiness when something nice happens or when you have been given a present"), repetition of key questions and concepts, fostering a cognitive routine, generalization and discussion. Children could verbalize their response or the key concepts, but they could also point to the emotion or the concept associated with the correct answer on the visual materials. Because the children were in groups, they could exchange views or get help from their peers. The effectiveness of this program was observed by Jacobs and Nader-Grosbois (2020a) in children with IDs. Children who received the training improved their understanding of affective and cognitive mental states, with greater progress in cognitive ToM. After the training, teachers described the children from the experimental groups as more socially adjusted, i.e. more polite, disciplined and responsive to others during social situations with peers. However, parents noticed no improvement in social adjustment or emotion regulation skills (Jacobs \& Nader-Grosbois, 2020a).

“SIP program for children" (Jacobs \& Nader-Grosbois, 2018b, 2020b)

This SIP program is based on the SIP model (Crick \& Dodge, 1994) and on a review of studies using SIP training on preschoolers at risk or not at risk of developmental disorder (i.e. Domitrovich, Cortes, \& Greenberg, 2007; Houssa, Jacobs, \& Nader-Grosbois, 2016; Houssa \& Nader-Grosbois, 2016; Houssa, Nader-Grosbois, \& Jacobs, 2014; Pears \& Moses, 2003; Shure, 1993; Webster-Stratton 
\& Hammond, 1997) and on children, adolescents or adults with IDs (i.e. Anderson \& Kazantzis, 2008; Crites \& Dunn, 2004; Jacobs et al., 2016; Nestler \& Goldbeck, 2011; O’Reilly \& Peterson, 2014) or autistic spectrum disorders (i.e. Bernard-Opitz, Sriram, \& Nakhoda-Sapuan, 2001; Radley, Ford, Battaglia, \& McHugh, 2014). The program aimed to foster social problem-solving abilities as well as the correct use of SIP in positive situations (such as prosocial situations or cooperation) and negative situations (such as provocation, social exclusion, conflict, transgression, frustration, or ambiguity) equally. By supporting their SIP skills, the goal was also to help children to identify the relevant cues and the appropriateness or inappropriateness of certain forms of social behavior and to avoid hostile attribution. This last goal was worked on by encouraging children to think about possible justifications for behavior in social situations in terms of the relation between the protagonists and social rules or conventions. The sessions were created to closely reflect the order of SIP steps and to increase in complexity over time, but also to take account of the weaknesses and strengths of children with IDs, as well as their zone of proximal development. The children attended eight 45-minute sessions run by two experimenters, twice a week, in subgroups of 3 to 4 . A set of instructions guided the experimenters and ensured that the sessions were run properly, although some adaptation was possible to the level of each subgroup. Materials (i.e. games, videos, pictures, images or picture books) presented hypothetical positive and negative social situations between two or more protagonists. These situations were chosen because they were very likely to have been experienced during interactions with peers or adults by children. Each of the eight sessions was organized the same way: it started with a brief reminder of the last session, followed by 1 to 3 SIP activities and finally the reading of a picture book. The techniques reflected the program goals and included repetitive sequences of questions to promote a cognitive routine, self-verbalization, discussion, generalization and connection with the children's own experiences. The key questions were represented on pictures, so children could either verbalize or point to the answer. Children who participated in the "SIP program for children" improved their ability to detect and explain whether and why a behavior was socially appropriate or not. They were also perceived by their parents as more socially adjusted and seemed to regulate their emotions better (Jacobs \& Nader-Grosbois, 2020b).

Commonalities and differences between ToM and SIP programs for children (Jacobs \& Nader-Grosbois, 2020a, 2020b)

The commonalities and differences are described in more detail in Appendix A. The timing and design of the sessions were similar: 45 minutes per session, twice a week for one month. Each session was attended by a subgroup of 3 to 4 children. Because the children were in groups, they could discuss and share their different opinions, leading to socio-cognitive debate. Children were given turns at speaking to ensure that each of them had the same speaking time. Each session targeted the program's general objectives but also specific session goals. The complexity of the sessions gradually increased in accordance with ToM devel- 
opment and SIP steps progression. Standardized sets of instructions provided guidance and ensured that each training session was run properly. However, a pretest evaluation was also conducted to identify the children's strengths and weaknesses and adapt each session to the subgroup, in order to foster emerging abilities and consolidate core skills. For example, experimenters ensured that emotions were recognized before introducing the cause of emotions, or reinforced the identification and interpretation of relevant socio-emotional cues before fostering goal clarification in social situations. The two programs are oriented to strengthen children's competences by taking their zone of proximal development into account. Children's potential for improvement from the programs will therefore differ according to their core competences. Some of the materials used in the two programs were similar (pictures, games and picture books), but differed in the kind of situations presented. The materials in the ToM training elicited either affective or cognitive mental states, whereas those in the SIP training related to negative and positive critical social situations. The situations described in the SIP training featured two or more protagonists and were designed to improve the understanding of the intersubjective nature of social situations. In these social situations, the protagonists could be either the victim or the perpetrator. Children could therefore identify with the protagonists. The techniques used in the two programs were quite similar, but targeted either ToM or SIP abilities. Visual materials were used in the two programs to represent either the key concepts or the key questions. This helped to compensate for the varying difficulties experienced by children with IDs in relation to executive functions or language. The techniques used required varying degrees of working memory skills. Likewise, the programs placed differing demands on the executive functions. In the ToM training, the children had to disregard their own perspective in order to take a protagonist's perspective. In SIP training, they had to disregard distractor stimuli to encode relevant social cues. The ToM program required abstraction while the SIP program made processes conscious in each step. Both programs served as interventions towards cognitive and socio-cognitive goals.

\section{Results}

\subsection{Sample Characteristics}

Table 1 presents average scores and standard deviations for the sample's demographic and individual characteristics, including scores in ToM, SIP and social adjustment, as well as the between-group comparisons at pretest. These results show that there was no difference between the three groups at pretest. Details of ages were given above in the description of the sample. Regarding demographic data, the families displayed a low socio-economic status. On a nine-level scale describing range of monthly income from 0 - 500 euros to 4000 euros or more, parents reported a low income $(M=3.14)$, with a mean monthly income (salaries of the two parents and benefits) of 1000 to 1500 euros, compared to a mean monthly salary in Belgium of about 1527 euros. Concerning parents' level of education, 
Table 1. Demographic and individual characteristics and competences in ToM, SIP and teachers' perception of social adjustment at pretest: mean scores and standard deviations for each group and between-group comparisons.

\begin{tabular}{|c|c|c|c|c|c|}
\hline & \multirow[t]{2}{*}{ Variables } & $\begin{array}{l}\text { Control } \\
\text { group } \\
(n=15)\end{array}$ & $\begin{array}{c}\text { ToM } \\
\text { Experimental } \\
\text { group } \\
(n=15)\end{array}$ & $\begin{array}{c}\text { SIP } \\
\text { Experimental } \\
\text { group } \\
(n=15)\end{array}$ & \multirow[t]{2}{*}{$\chi^{2} / F$} \\
\hline & & $M(S D)$ & $M(S D)$ & $M(S D)$ & \\
\hline Sex (\% boys) & & $86 \%$ & $66 \%$ & $47 \%$ & 5.4 \\
\hline CA (in months) & & $109.6(12.51)$ & $104.13(25.37)$ & 0.32 & 0.32 \\
\hline GDA (in months) & & $63.47(16.18)$ & $61.67(12.57)$ & 0.07 & 0.07 \\
\hline VDA (in months) & & $62.1(15.85)$ & $60.77(13.27)$ & 0.06 & 0.06 \\
\hline \multirow[t]{5}{*}{ Family variables } & Family income & $3.20(1.15)$ & $3.64(0.81)$ & 9.99 & 9.99 \\
\hline & Mothers' education $(\max =7)$ & $2.45(1.44)$ & $2.63(1.6)$ & 18.16 & 18.16 \\
\hline & Fathers' education $(\max =7)$ & $3.33(1.22)$ & $3.83(1.6)$ & 12.33 & 12.33 \\
\hline & Mother-child conversations about emotions & $2.1(0.54)$ & $2.39(0.83)$ & 0.77 & 0.77 \\
\hline & Father-child conversations about emotions & $2.04(0.79)$ & $3.06(0.94)$ & 1.96 & 1.96 \\
\hline \multirow[t]{12}{*}{ ToM } & ToM Task Battery total $(\max =15)$ & $8.07(2.52)$ & $8.33(3.15)$ & $8.33(2.13)$ & 0.05 \\
\hline & Affective ToM Task Battery $(\max =6)$ & $4.8(1.15)$ & $4.93(1.38)$ & $5.27(0.88)$ & 0.73 \\
\hline & Cognitive ToM Task Battery $(\max =6)$ & $2.64(1.15)$ & $2.86(1.46)$ & $2.93(1.62)$ & 0.34 \\
\hline & Mixed ToM Task Battery $(\max =3)$ & $0.92(0.95)$ & $0.64(1.08)$ & $0.13(0.35)$ & 2.38 \\
\hline & ToM emotions $(\max =12)$ & $6.9(1.61)$ & $7.33(2.77)$ & $8.133(1.87)$ & 2.45 \\
\hline & ToM emotions—causes $(\max =6)$ & $3.47(0.85)$ & $3.80(1.59)$ & $4.17(1.25)$ & 1.14 \\
\hline & ToM emotions-consequences $(\max =6)$ & $2.93(1.31)$ & $3.53(1.41)$ & $3.97(1.38)$ & 2.16 \\
\hline & ToM beliefs $(\max =5)$ & $2.43(1.31)$ & $3.13(1.42)$ & $3.43(1.35)$ & 2.14 \\
\hline & ToM Inventory $(\max =20)$ & $12.46(3.51)$ & $12.5(3.43)$ & $13.03(3.51)$ & 0.64 \\
\hline & ToM Inventory-Factor 1 & $13.03(4.56)$ & $10.88(3.65)$ & $11.59(4.35)$ & 0.53 \\
\hline & ToM Inventory-Factor 2 & $15.05(2.58)$ & $14.61(3.34)$ & $15.05(2.39)$ & 0.11 \\
\hline & ToM Inventory-Factor 3 & $15.86(2.45)$ & $13.65(4.7)$ & $13.43(4.88)$ & 1.36 \\
\hline \multirow[t]{7}{*}{ SIP } & RES total $(\max =140)$ & $61.47(20.18)$ & $65.27(28.26)$ & $64.07(15.9)$ & 0.12 \\
\hline & Judgment score on appropriate vignettes $(\max =2)$ & $1.77(0.34)$ & $1.47(0.72)$ & $1.8(0.42)$ & 1.89 \\
\hline & Judgment score on inappropriate vignettes $(\max =2)$ & $1.81(0.19)$ & $1.84(0.29)$ & $1.78(0.22)$ & 0.23 \\
\hline & Identification score on appropriate vignettes $(\max =1)$ & $0.83(0.17)$ & $0.72(0.38)$ & $0.89(0.18)$ & 1.65 \\
\hline & Identification score on inappropriate vignettes $(\max =1)$ & $0.72(0.16)$ & $0.82(0.26)$ & $0.84(0.13)$ & 1.79 \\
\hline & Justification score on appropriate vignettes $(\max =7)$ & $1.59(1.14)$ & $2.32(1.66)$ & $2.13(1.39)$ & 1.09 \\
\hline & Justification score on inappropriate vignettes $(\max =7)$ & $2.08(1.34)$ & $2.09(1.41)$ & $1.8(0.93)$ & 0.26 \\
\hline \multirow[t]{8}{*}{ Social adjustment } & EASE total_Teachers $(\max =98)$ & $48.30(17.19)$ & $54.08(17.94)$ & $51.75(20.07)$ & 0.28 \\
\hline & EASE ToM_Teachers $(\max =52)$ & $25(8.55)$ & $26.92(9.23)$ & $26.25(9.61)$ & 0.13 \\
\hline & EASE social skills_Teachers $(\max =46)$ & $23.30(8.93)$ & $27.15(9.38)$ & $25.5(10.76)$ & 0.44 \\
\hline & EASE total_Parents $(\max =98)$ & $59.07(18.66)$ & $57.38(19.35)$ & $55.14(16.01)$ & 0.17 \\
\hline & EASE ToM_Parents $(\max =52)$ & $28.93(9.80)$ & $27.85(10.51)$ & $25.71(7.78)$ & 0.42 \\
\hline & EASE social skills_Parents $(\max =46)$ & $30.14(9.44)$ & $29.38(9.17)$ & $29.36(8.68)$ & 0.03 \\
\hline & CBCL Externalizing Behaviors & $16.47(10.44)$ & $19.25(11.51)$ & $17.36(11.06)$ & 0.21 \\
\hline & CBCL Internalizing Behaviors & $17.53(9.03)$ & $18.42(10.04)$ & $19(8.76)$ & 0.08 \\
\hline
\end{tabular}

a. ToM = Theory of Mind; SIP = Social information processing; CA = Chronological Age; GDA = Global Developmental Age; RES = Problem-solving task; EASE $=$ Social Adjustment Scale for Children $\mathrm{CBCL}=$ Child Behavior Checklist . 
in the control and ToM experimental groups, the mean levels corresponded to primary and secondary school for mothers and fathers respectively, whereas for mothers and fathers in the SIP experimental group, the mean respective levels were an apprenticeship contract and a bachelor's degree. However, no difference has been found between the three groups. It revealed a certain homogeneity of cultural and socioeconomic status between the three groups. Although there is no standard measure of ToM, SIP or social adjustment, we were able to gain some indications of strengths and weaknesses. To do so, we analyzed whether scores were below or above average. Overall, children displayed ToM scores at or above the mean, except for the cognitive and mixed subscores of the ToM Task Battery. The total score on the problem-solving task was below average, although only the two justification scores were below average. Further analyses of the justification scores and in particular the occurrence of a certain kind of justification (see Table 2) showed that children in the SIP experimental group used more descriptive justification than children in the control group $(F=3.66 ; p=0.034)$. Social adjustment scores generally corresponded to the average. Finally, the CBCL scores indicated that children in the three groups displayed internalizing behaviors at a clinical level $(>17)$ and no externalized problems, according to their parents.

\subsection{The Effects of the ToM and SIP Training on Social Cognition and Adjustment}

Table 3 presents the results of the repeated measures ANOVAs comparing the pre- and post-tests for the control and experimental groups. Table 4 presents the

Table 2. Occurrence of each level of justification (incorrect, descriptive, intersubjective or related to social rules) at pretest in the problem-solving task.

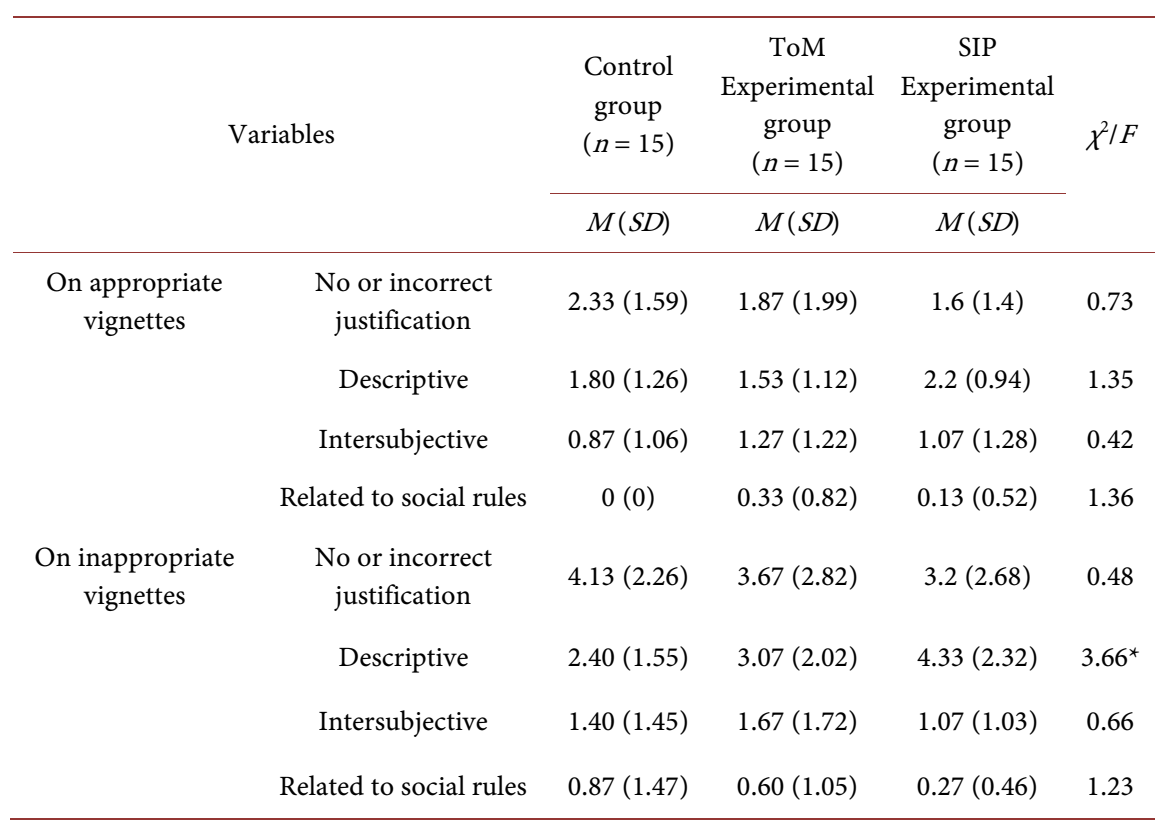

a. $\mathrm{ToM}=$ Theory of Mind; SIP $=$ Social information processing; ${ }^{*} p=0.034$. 
Table 3. Repeated measures ANOVAs on ToM, SIP and Social adjustment.

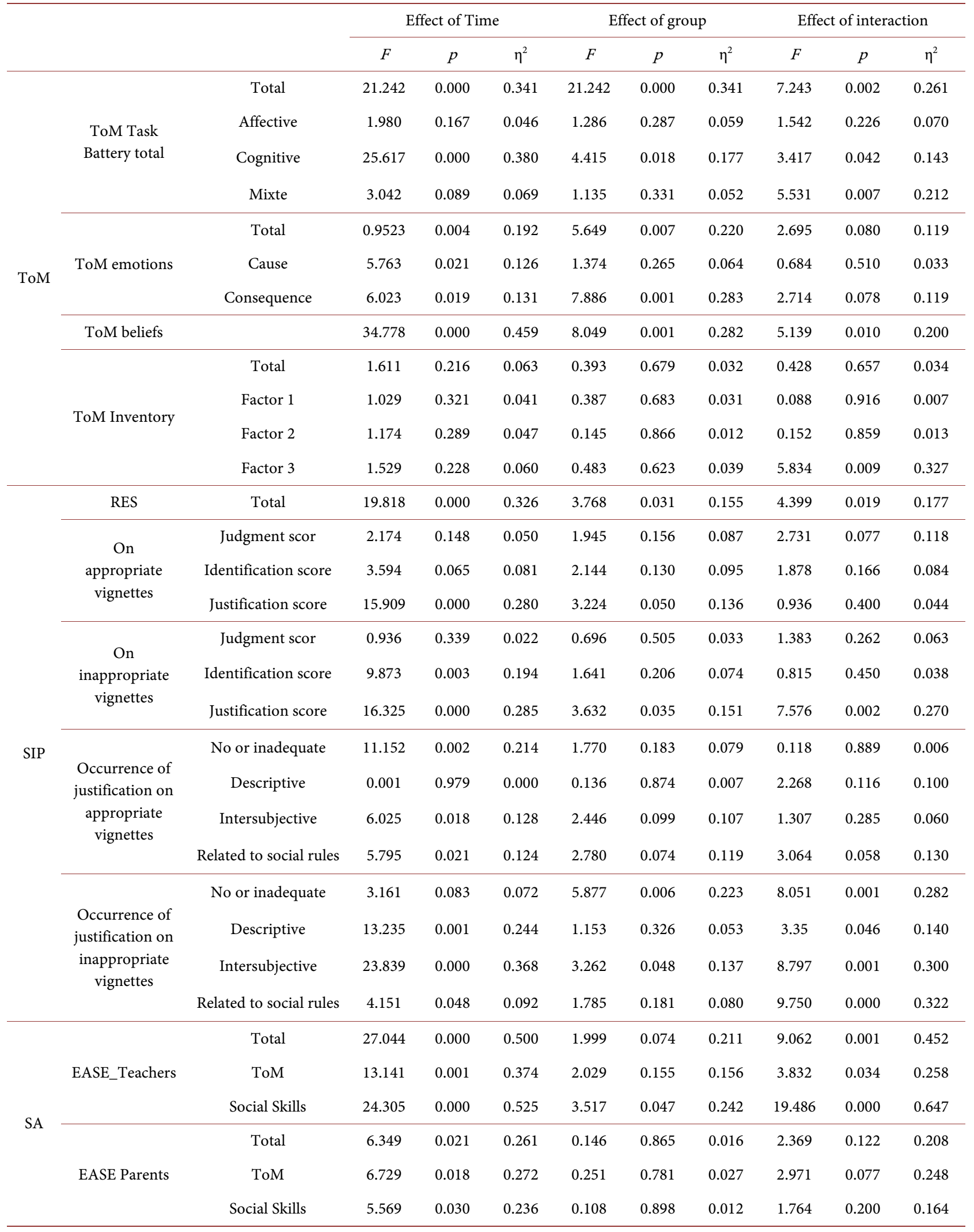

a. ToM = Theory of Mind; SIP = Social information processing; RES = Problem-solving task; SA = Social Adjustment; EASE = Social Adjustment Scale for Children. 
Table 4. ToM, SIP and social adjustment competences at post-test: mean scores and standard deviations for each group and between-group comparisons.

\begin{tabular}{|c|c|c|c|c|c|c|}
\hline & \multirow[t]{2}{*}{ Variables } & $\begin{array}{l}\text { Control } \\
\text { group } \\
(n=15)\end{array}$ & $\begin{array}{c}\text { ToM } \\
\text { Experimental } \\
\text { group } \\
(n=15)\end{array}$ & $\begin{array}{c}\text { SIP } \\
\text { Experimental } \\
\text { group } \\
(n=15)\end{array}$ & \multirow[t]{2}{*}{$F$} & \multirow[t]{2}{*}{ Partial $\eta^{2}$} \\
\hline & & $M(S D)$ & $M(S D)$ & $M(S D)$ & & \\
\hline \multirow[t]{12}{*}{ ToM } & ToM Task Battery total $(\max =15)$ & $7.8(2.37)$ & $11.2(2.4)$ & $10.79(2.04)$ & $9.86^{* * * *}$ & 0.32 \\
\hline & Affective ToM Task Battery $(\max =6)$ & $4.73(1.16)$ & $5.47(0.92)$ & $5.36(0.75)$ & 2.54 . & \\
\hline & Cognitive ToM Task Battery $(\max =6)$ & $2.87(1.64)$ & $4.6(1.06)$ & $4.5(0.94)$ & $8.89^{* * *}$ & 0.30 \\
\hline & Mixed ToM Task Battery $(\max =3)$ & $0.27(0.59)$ & $1.13(1.25)$ & $0.93(1.07)$ & 3.02 & \\
\hline & ToM emotions $(\max =12)$ & $6.5(1.36)$ & $8.96(2.71)$ & $9.11(1.82)$ & $7.65^{\star *}$ & 0.28 \\
\hline & ToM emotions-causes $(\max =6)$ & $3.73(1.01)$ & $4.46(1.41)$ & $4.39(1.25)$ & 1.59 & \\
\hline & ToM emotions-consequences $(\max =6)$ & $2.83(1.25)$ & $4.57(1.67)$ & $4.75(0.93)$ & $9.43^{* * * *}$ & 0.32 \\
\hline & ToM beliefs $(\max =5)$ & $2.73(0.99)$ & $4.6(0.66)$ & $4.36(0.82)$ & $21.88^{* * * *}$ & 0.52 \\
\hline & ToM Inventory $(\max =20)$ & $13.78(7.31)$ & $14.57(4.15)$ & $14.59(3.82)$ & 0.08 & \\
\hline & ToM Inventory- Factor 1 & $12.91(11.07)$ & $13.06(5.61)$ & $13.29(5.18)$ & 0.01 & \\
\hline & ToM Inventory-Factor 2 & $15.55(5.31)$ & $15.86(2.81)$ & $15.43(2.98)$ & 0.03 & \\
\hline & ToM Inventory-Factor 3 & $13.28(4.49)$ & $16.03(3.75)$ & $16.32(2.95)$ & 2.24 & \\
\hline \multirow[t]{7}{*}{ SIP } & RES total $(\max =140)$ & $63.53(21.02)$ & $84.20(19.98)$ & $92.43(11.49)$ & $9.87^{* * * *}$ & 0.32 \\
\hline & Judgment score on appropriate vignettes $(\max =2)$ & $1.61(0.63)$ & $1.84(0.33)$ & $2.01(0.32)$ & 3.21 & \\
\hline & Judgment score on inappropriate vignettes $(\max =2)$ & $1.76(0.23)$ & $1.9(0.19)$ & $1.89(0.21)$ & 1.91 & \\
\hline & Identification score on appropriate vignettes $(\max =1)$ & $0.81(0.29)$ & $0.91(0.18)$ & $0.99(0.05)$ & $3.03^{\dagger}$ & 0.13 \\
\hline & Identification score on inappropriate vignettes $(\max =1)$ & $0.84(0.13)$ & $0.92(0.15)$ & $0.88(0.15)$ & 0.96 & \\
\hline & Justification score on appropriate vignettes $(\max =7)$ & $2.29(1.59)$ & $3.25(1.34)$ & $3.6(1.11)$ & $3.6^{\star}$ & 0.15 \\
\hline & Justification score on inappropriate vignettes $(\max =7)$ & $1.84(1.11)$ & $3.21(1.45)$ & $3.84(0.85)$ & $11.25^{* * * *}$ & 0.35 \\
\hline \multirow[t]{6}{*}{ Social adjustment } & EASE total_Teachers $(\max =98)$ & $46.90(16.17)$ & $59.31(16.85)$ & $72.17(14.34)$ & $10.45^{* * *}$ & 0.43 \\
\hline & EASE ToM_Teachers $(\max =52)$ & $24.20(7.76)$ & $32.08(8.87)$ & $36.29(6.26)$ & $6.18^{* *}$ & 0.34 \\
\hline & EASE social skills_Teachers $(\max =46)$ & $22.70(9.08)$ & $29.23(8.15)$ & $37.14(5.58)$ & $9.22^{* * *}$ & 0.43 \\
\hline & EASE total_Parents $(\max =98)$ & $61(17.35)$ & $72(17.72)$ & $68.57(16.18)$ & 0.82 & 0.08 \\
\hline & EASE ToM_Parents $(\max =52)$ & $29.42(8.71)$ & $36.25(7.27)$ & $33.57(6.8)$ & 1.33 & 0.12 \\
\hline & EASE social skills_Parents $(\max =46)$ & $31.58(9.2)$ & $35.75(10.72)$ & $35(9.92)$ & 0.43 & 0.04 \\
\hline
\end{tabular}

a. ToM = Theory of Mind; SIP = Social information processing; RES = Problem-solving task; ${ }^{*} p<0.05,{ }^{* *} p \leq 0.01,{ }^{* * *} p \leq 0.001,{ }^{* * * *} p=0.000 ;{ }^{\dagger} p=0.059$.

mean and standard deviation for each group at post-test. In terms of ToM measures, significant effects of time were observed, with the exception of the affective and mixed subscores in the ToM Task Battery and the ToMI scores. Significant effects of group were observed in the following scores: cognitive ToM Task Battery, ToM emotion consequences and ToM beliefs. Significant group by time interaction effects were obtained in some tasks, for example in the ToM Task Battery, and more precisely in the cognitive and mixed scores. Significant group by time interaction effects were also observed in ToM beliefs and in factor 
3 of the ToMI. A group by time interaction effect was marginally significant for the ToM-emotions task, and more precisely for the understanding of consequences subscore. Bonferroni posthoc indicated significant differences between children in the control group and children in each experimental group.

As it can be seen in Table 3, significant effects of time and effects of group were observed for total RES, the SIP measure. Results revealed significant effects of time and effects of group concerning justification scores on both appropriate and inappropriate vignettes. Whereas only a significant effect of time was detected in the identification score on inappropriate vignettes. Significant group by time interaction effects were observed in the RES total $\left(F=4.399 ; p=0.019 ; \eta^{2}=\right.$ $0.177)$ and in the justification score on inappropriate vignettes $(F=7.576 ; p=$ $\left.0.002 ; \eta^{2}=0.270\right)$. Further analysis indicated significant group by time interaction effects for each of the four types of justification on inappropriate vignettes. A trend was observed concerning group by time interaction in the judgment score on appropriate vignettes. Bonferroni post-hoc analyses showed significant differences between the control and SIP experimental groups on RES total and the justification score on inappropriate vignettes. Concerning the judgment score on appropriate vignettes, significant differences were observed between the control group on one hand and the two experimental groups on the other hand. Lastly, concerning the occurrence of intersubjective justification on inappropriate vignettes, the Bonferroni post-hoc indicated a marginally significant difference between the control and the ToM experimental groups.

Finally, in terms of social adjustment, significant effects of time were observed for the global score and the two subscores, when the measure was completed by parents and teachers. Significant group by time interaction effects $(F=9.062 ; p=$ $\left.0.001 ; \eta^{2}=0.452\right)$ was obtained only for scores related to the perception of teachers. A significant effect of group was only obtained in the subscore relating to social skills. Significant group by time interaction effects were observed for the global scale and the two subscales. Bonferroni post-hoc indicated no significant difference between groups. However, from a qualitative point of view, the SIP experimental group seemed to improve the most in terms of their social adjustment abilities and in particular their social skills.

\subsection{Impact of the Programs on the Children's Social Cognition Profiles}

To investigate which variables relating to children's social cognition contribute to explaining the effectiveness of the programs, hierarchical multiple regression analyses were conducted, after controlling for the pretest results and individual characteristics: 1) in Model 1, pretest results were entered; 2) in Model 2, pretest results and chronological and developmental ages were entered; 3) in Model 3, pretest results, individual characteristics and group condition (namely ToM experimental group vs. control group and SIP experimental group vs. control group) were entered. The results indicated whether attendance of the ToM and SIP training programs explained part of the variance of the measure at post-test. 


\subsubsection{Impact of the Programs on the Children's ToM Profiles}

As shown in Table 5, the total for the ToM Task Battery at post-test was explained by pretest results and by both the ToM and SIP programs. The cognitive and mixed subscores were explained by both the ToM and SIP programs, while only $8 \%$ of the variance in the affective subscore at post-test was explained by the ToM program alone. After controlling for pretest results in ToM-emotions and for children's ages, both ToM and SIP programs predicted 14\% of the variance of the ToM-emotions at post-test. However, beta and p-values were higher for the ToM training condition than for the SIP training condition. Similar results were obtained for the subscore relating to the understanding of consequences of emotions: after controlling for pretest results, ToM and SIP programs predicted $15.5 \%$ of the variance at post-test. After controlling for pretest result in ToM-emotions-causes and for individual ages, the ToM training condition closely predicted $2.8 \%(p=0.059)$ of the variance in ToM-emotions relating to the understanding of causes at post-test. After controlling for pretest results in ToM-beliefs and for children's ages, both ToM and SIP programs predicted $33.1 \%$ of the variance in ToM-beliefs at post-test. Concerning the subscore relating to factor 3 of ToMI, after controlling for pretest result and children's ages, SIP training significantly predicted and ToM training closely predicted ( $p=$ $0.056) 12.7 \%$ of the variance in ToMI-factor 3 at post-test.

\subsubsection{Impact of the Programs on the Children's SIP Profiles}

As shown in Table 6, concerning the judgment score on inappropriate vignettes, $7.1 \%$ of the variance in the post-test result was explained by two predictors, chronological age and ToM training, in Model 3. 30.7\% of the variance in the identification scores on inappropriate vignettes at post-test was explained by pretest result and by chronological age, but not by group condition. Regarding justification scores, different results were obtained according to the kind of vignettes, namely appropriate vs. inappropriate. After controlling for pretest result for the justification score on appropriate vignettes and for individual ages, the SIP training condition predicted $9.2 \%$ of the variance in this justification score at post-test. It should be noted that ToM training also predicted a part of this variance at post-test, but only closely significant $(p=0.079)$. After controlling for pretest result for the justification score on inappropriate vignettes and for individual ages, SIP and ToM training conditions predicted $34.7 \%$ of the variance in this justification score at post-test. However, the SIP training condition explained more of this variance, with beta and p-values higher than those associated with the ToM training condition.

\section{Discussion}

The present study aimed to investigate whether ToM or SIP training was better at fostering social cognition and adjustment. Several previous studies have shown the effectiveness of ToM training for ToM abilities and of SIP training for SIP skills, except the short-term training study led by Jacobs et al. (2016), 
Table 5. Hierarchical multiple regression on ToM measures.

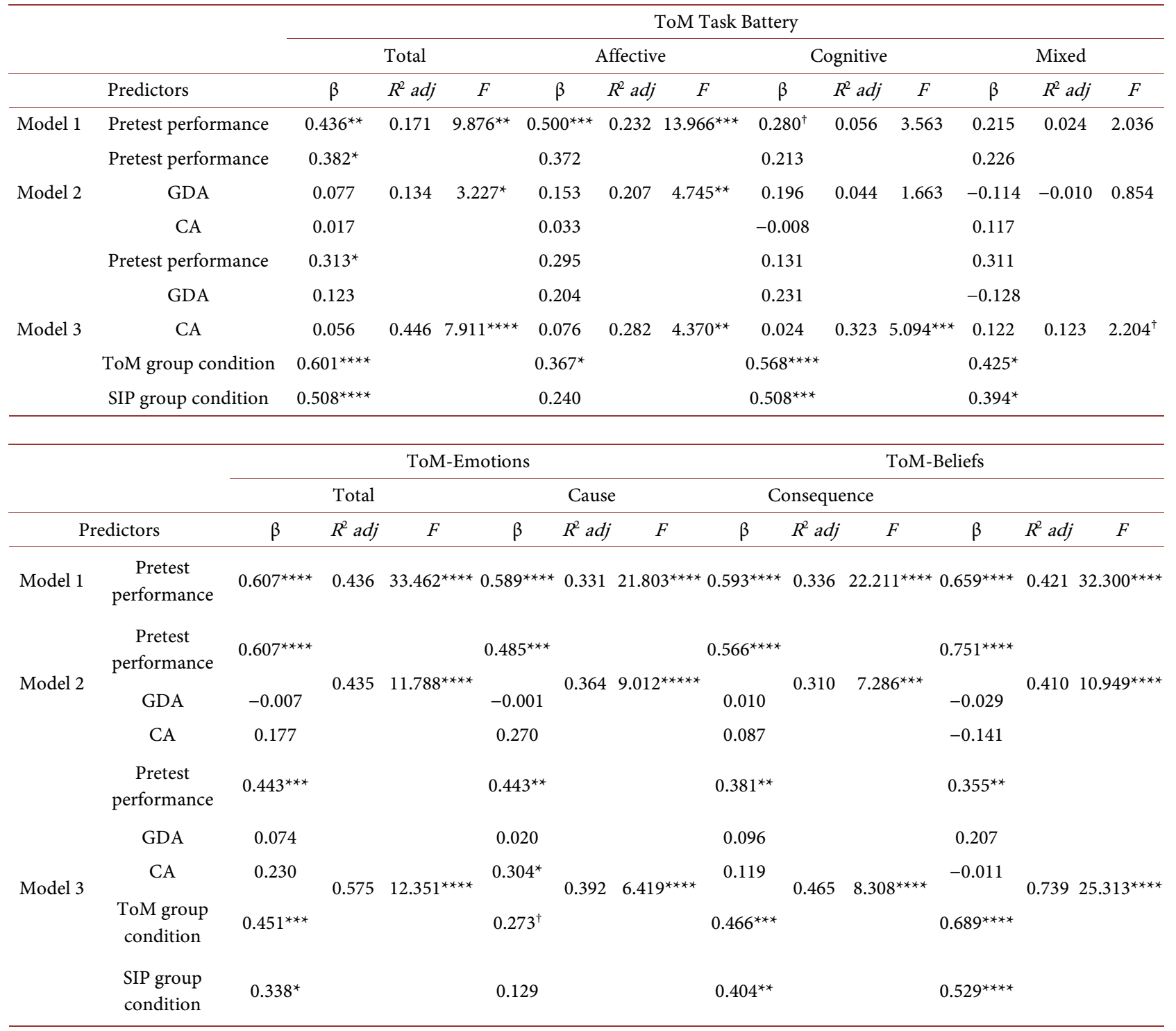

\begin{tabular}{|c|c|c|c|c|}
\hline & & \multicolumn{3}{|c|}{ ToMI } \\
\hline & & \multicolumn{3}{|c|}{ Factor 3} \\
\hline \multicolumn{2}{|c|}{ Predictors } & $\beta$ & $R^{2}$ adj & $F$ \\
\hline \multirow[t]{2}{*}{ Model 1} & Pretest performance & 0.162 & -0.013 & 0.673 \\
\hline & Pretest performance & -0.075 & & \\
\hline \multirow[t]{4}{*}{ Model 2} & GDA & -0.107 & 0.117 & 2.144 \\
\hline & CA & $0.547^{\star}$ & & \\
\hline & Pretest performance & 0.084 & & \\
\hline & GDA & 0.038 & & \\
\hline \multirow[t]{3}{*}{ Model 3} & $\mathrm{CA}$ & 0.383 & 0.244 & $2.678^{*}$ \\
\hline & ToM group condition & $0.419^{\dagger}$ & & \\
\hline & SIP group condition & $0.458^{*}$ & & \\
\hline
\end{tabular}

a. $\mathrm{ToM}=$ Theory of Mind; SIP = Social information processing; $\mathrm{CA}=$ Chronological Age; GDA = Global Developmental Age; $\beta=$ regression coefficient; $\mathrm{R}^{2}$ adj $=$ Total R squared; ${ }^{*} p<0.05 ;{ }^{* *} p<0.01 ;{ }^{* * *} p \leq 0.001 ;{ }^{* * *} p=0.000 ;{ }^{\dagger} p<0.08$. 
Table 6. Hierarchical multiple regression on SIP measures.

\begin{tabular}{|c|c|c|c|c|c|c|c|c|c|c|c|c|c|}
\hline & \multirow[b]{4}{*}{ Predictors } & \multicolumn{12}{|c|}{ RES } \\
\hline & & \multirow{2}{*}{\multicolumn{3}{|c|}{$\frac{\text { On appropriate vignettes }}{\text { Justification }}$}} & \multicolumn{9}{|c|}{ On inappropriate vignettes } \\
\hline & & & & & \multicolumn{3}{|c|}{ Judgment } & \multicolumn{3}{|c|}{ Identification } & \multicolumn{3}{|c|}{ Justification } \\
\hline & & $\beta$ & $R^{2}$ adj & $F$ & $\beta$ & $R^{2}$ adj $j$ & $F$ & $\beta$ & $R^{2}$ adj & $F$ & $\beta$ & $R^{2}$ adj & $F$ \\
\hline \multirow[t]{2}{*}{ Model 1} & Pretest performance & 0.219 & 0.025 & 2.111 & 0.270 & 0.051 & 3.309 & $0.474^{* * *}$ & 0.207 & $12.201^{\star * *}$ & 0.060 & -0.020 & 0.152 \\
\hline & Pretest performance & 0.210 & & & 0.115 & & & $0.435^{\star}$ & & & 0.020 & & \\
\hline \multirow[t]{4}{*}{ Model 2} & GDA & -0.152 & 0.025 & 1.373 & -0.149 & 0.214 & $4.897^{\star *}$ & -0.265 & 0.304 & $7.259^{* * *}$ & -0.087 & -0.025 & 0.657 \\
\hline & $\mathrm{CA}$ & 0.237 & & & $0.520^{\star *}$ & & & $0.397^{\star}$ & & & 0.238 & & \\
\hline & Pretest performance & 0.101 & & & 0.093 & & & $0.387^{*}$ & & & 0.095 & & \\
\hline & GDA & -0.087 & & & -0.136 & & & -0.246 & & & 0.114 & & \\
\hline \multirow[t]{3}{*}{ Model 3} & $\mathrm{CA}$ & 0.252 & 0.117 & 2.140 & $0.545^{\star * *}$ & 0.285 & $4.424^{\star *}$ & $0.440^{* *}$ & 0.307 & $4.813^{\star *}$ & 0.214 & 0.322 & $5.088^{* * *}$ \\
\hline & ToM group condition & 0.317 & & & $0.352^{*}$ & & & 0.183 & & & $0.481^{\star *}$ & & \\
\hline & SIP group condition & $0.396^{*}$ & & & 0.252 & & & -0.021 & & & $0.663^{\star * * *}$ & & \\
\hline
\end{tabular}

a. ToM = Theory of Mind; SIP = Social information processing; $\mathrm{CA}=$ Chronological Age; GDA = Global Developmental Age; RES = Problem-solving task; $\beta$ $=$ regression coefficient, R2adj $=$ Total R squared; ${ }^{*} p<0.05 ;{ }^{* *} p<0.01 ;{ }^{* *} p \leq 0.001 ;{ }^{* * *} p=0.000 ;{ }^{\dagger} p<0.09$.

no research has investigated the transfer effect of such training programs in children with IDs. Likewise, no previous study has explored whether ToM or SIP training interventions are more supportive of social adjustment in children with IDs. The present results supported the existence of a transfer effect which varies according to the kind of mental states (affective vs. cognitive) and social situations (positive vs. negative) involved, as well as specific effects of each training program on social adjustment.

The effectiveness of ToM training for children with IDs is known. Depending on the goals, techniques and material, suitable training could enhance the understanding of affective (Jacobs et al., 2016; Jacobs \& Nader-Grosbois, 2020a; Lachavanne \& Barisnikov, 2013; Stewart \& Singh, 1995) and/or cognitive mental states (Jacobs et al., 2016; Jacobs \& Nader-Grosbois, 2020a). The ToM program for children used in the present research and previously by Jacobs and Nader-Grosbois (2020a) seems to foster cognitive ToM in particular. However, the SIP program for children also appears to enhance the understanding of cognitive mental states: children who received this SIP training improved their result in the cognitive subscore of ToM Task Battery and in ToM-beliefs. These findings could be explained by the fact that to process social information appropriately, children have to take other people's perspective and understand their intentions, beliefs or false beliefs. In the SIP program, the experimenter used key questions such as "Was that done on purpose or was it an accident?", "What would you do?" or "If he does that, will the other child be his friend?". Such questions required an understanding of cognitive mental states such as intentions and perspective-taking. Some authors have supported this hypothesis about a link between cognitive ToM and the interpretation of social cues (Mazza et al., 2017) or 
the prosocial behavior of helping (Conte, Grazzani, \& Pepe, 2018) in typically developing preschoolers. The relation between ToM and SIP in negative and positive situations has also been observed in children with IDs (Jacobs et al., 2020). Likewise, hierarchical regression analyses in the present study also supported this conclusion. ToM training as much as SIP training explained the variance at post-test in performance-based measures of cognitive ToM. This transfer effect was also observed by Houssa et al. (2016); Houssa, Nader-Grosbois, \& Jacobs (2014) in samples of preschoolers with and without externalizing behaviors. Attendance of SIP training explained parents' perception of improvements in cognitive ToM (score ToMI-factor 3) as much as attendance of ToM training. Similarly, in terms of the results for affective ToM, and in particular ToM-emotions, SIP training seemed to foster the understanding of the consequences of emotions. Both trainings explained $15 \%$ of the variance in the understanding of consequences of emotions at post-test. The same result was found by Houssa et al. (2016) in preschoolers displaying externalizing behaviors. This could be explained by the fact that when children process social information, they encode and interpret social and emotional cues. Crick \& Dodge (1994), Lemerise \& Arsenio (2000) and Lemerise et al. (2005) have already emphasized the role of emotions in SIP. Children have to identify their own emotion and its consequence to act in a prosocial way. If a child's toy is accidentally broken by his friend, he needs to understand that although he feels sad, his friend's action was unintentional and he can ask his friend for help. According to Jacobs et al. (2020), children with IDs use affective ToM particularly in negative social situations, for example when faced with hostile intentions, provocation, frustration or rejection.

While the effectiveness of SIP training on SIP skills has been demonstrated in this study and in others (Anderson \& Kazantzis, 2008; Crites \& Dunn, 2004; Jacobs et al., 2016; Jacobs \& Nader-Grosbois, 2020b; Nestler \& Goldbeck, 2011; O’Reilly \& Peterson, 2014), the ToM program also improved these skills. After receiving ToM training, children with IDs showed better ability to judge negative social situations and explained inappropriate behaviors by considering the relation between protagonists (e.g. "He hurt the other girl", "She will be sad because he isn't sharing"). These findings were revealed by both repeated measures ANOVAs and hierarchical multiple regression. They were in line with studies supporting the importance of emotions (Crick \& Dodge, 1994; Lemerise \& Arsenio, 2000; Lemerise et al., 2005) or ToM (Conte et al., 2018; Mazza et al., 2017) in processing social information. Recently, Jacobs et al. (2020) also underlined that affective ToM is particularly used by children with IDs in negative social situations. Stimulation of affective ToM would foster problem-solving skills during negative social situations. These transfer effects between ToM and SIP skills emphasized the existence of a common underlying cognitive process. To use ToM abilities and SIP appropriately, children have to use working memory (Dennis, Agostino, Roncadin, \& Levin, 2009; Lecce \& Bianco, 2018) and inhibition (Perner, Lang, \& Kloo, 2002; van Nieuwenhuijzen \& Vriens, 2012). 
Beyond these effects, ToM training and SIP training are both effective at improving the social adjustment of children with IDs. Numerous studies have reported the predictive value of ToM (i.e. Deneault \& Ricard, 2013) and SIP (i.e. Crick \& Dodge, 1994) for social adjustment in typically developing children. Other studies have supported the existence of bidirectional links, such as Yeates et al. (2007). The present findings highlight a causal contribution of both ToM and SIP to social adjustment in children with IDs. While children with IDs are perceived as less socially competent by their parents and teachers than typically developing children (Thirion-Marissiaux \& Nader-Grosbois, 2008c), social inclusion is a major issue in society today. The effectiveness of these two programs in improving social adjustment is therefore a very encouraging result. However, this effect was only reported by teachers. This could be explained by the fact that teachers observed the children during interaction with both peers and adults. When looking at results from a qualitative perspective, the SIP program seemed to foster better social adjustment, especially in the area of social skills. This type of training favored social situations of the kind commonly experienced by children, featuring several protagonists. The situations reflected reality and fostered the generalization of learning. This specific impact of SIP training could also be explained by the fact that the SIP process could be used consciously (Dodge, 2014). Dodge (2014) underlined that while generally used unconsciously, SIP skills required the conscious detection of cues or the generation of very new responses in complex social situations. An awareness of this process was ensured during all the sessions by the use of key questions in the specific order referring at SIP steps. This technique may have activated prosocial behaviors, fostering social interaction and adjustment in children with IDs.

Limitations in the present study and future possibilities have to be considered. Concerning the method, the sample size was quite small, as recruitment was restricted by the strict inclusion criteria described above. It would be interesting to replicate the study design with a larger sample and with children displaying specific syndromes such as Down syndrome. In terms of evaluation, assessing social adjustment with a performance-based measure would be a way of exploring in more detail the causal contribution of either ToM or SIP to social adjustment in different contexts, i.e. during interactions with peers or adults at school or at home. Another family variable could be added: emotion-related socialization behaviors of parents. Recent studies have underlined the difference in behaviors used by parents with or without children with IDs (Jacobs, Mazzone, Simon, \& Nader-Grosbois, 2019b; Rodas, Chavira, \& Baker, 2017; Rodas, Zeedyk, \& Baker, 2016) and investigated the role of these behaviors in social adjustment (Jacobs et al., 2019b) and in ToM and emotion regulation (Jacobs, Mazzone, Simon, \& Nader-Grosbois, 2019a). In light of these recent findings and considering support needed by parents in the present study, it would be interesting to implement a parental intervention to foster social cognition in children with IDs and compare its effectiveness with that of training for the children. Clinicians would then have a clearer understanding of whether interventions should focus on 
children, parents, or both children and parents, to support social inclusion. Finally, a follow-up measure would have provided more information about the generalization of knowledge. It may have taken six months or even longer for children who received ToM training to show improvements in their social adjustment.

\section{Psychoeducational implications}

The results show the positive quantitative and qualitative effects of both ToM and SIP trainings. It establishes that the two training procedures improve social cognition and adjustment in children with IDs. This study set out pointers for the successful implementation of a training program with the objective to improve social cognition, social adjustment and inclusion. It could help psychologists specializing in special education, teachers and parents by providing a basis for training plans using a specific procedure, techniques and materials. The study clearly demonstrates the importance of an evaluation at pretest of children's competences. This makes it possible to take account of the proximal zone of development, consolidate core competences and foster emerging abilities. The use of groups in training, when possible, is very rewarding for children and experimenters, but sometimes a child needs specific and individual support. The gap with others may widen between two sessions. If the psychologist has the possibility of offering an individual session to a child who is falling behind in this way, he or she will continue to benefit from the rest of the training. The use of augmented alternative language will be useful if it is commonly employed by children. Situations used in the materials need to evoke real-life experience for children to foster generalization. The results highlight the need to make the process as concrete and conscious as possible, in particular by using cognitive routines (key questions or concepts) illustrated in visual materials. It was not possible to implement all of these suggestions because of the study's scientific framework, but they are worthy of consideration by clinicians.

In light of the profile of children with IDs and the present findings, with a view to enhancing social cognition, adjustment and interactions it would be useful in clinical practice and in future research to combine ToM and SIP programs with executive function stimulation. As execution functions are the process underlying ToM and SIP (Li et al., 2014; Van Rest et al., 2018), a combination of these programs and executive function stimulation would improve effectiveness. A very recent study demonstrated the effectiveness of a combined intervention focusing on social cognition and executive function in typically developing preschoolers in a school setting (Honoré, Houssa, Volckaert, Noël, \& Nader-Grosbois, Submitted). Finally, as we know that children with IDs display difficulties in social functioning (Schalock et al., 2010) and are at higher risk of developing certain behavioral problems (Dekker, Koot, van der Ende, \& Verhulst, 2002; Hauser-Cram \& Woodman, 2016; Thirion-Marissiaux \& Nader-Grosbois, 2008c), early intervention, and training in particular, is crucial. The sooner we intervene, the more chance we have of limiting social difficulties and fostering well-being and quality of life for children with IDs. 


\section{Acknowledgements}

We are grateful the Marguerite-Marie Delacroix Foundation and the Chair Baron Frère for its financial support for this research. We wish to thank all children, parents and teachers for their participation in this study. We are finally thankful to Poline Simon for their help in collecting data.

\section{Conflicts of Interest}

The authors declare no conflicts of interest regarding the publication of this paper.

\section{References}

Achenbach, T. M. (1991). Manual for the Child Behavior Checklist/4-18 and 1991 Profile.

Anderson, G., \& Kazantzis, N. (2008). Social Problem-Solving Skills Training for Adults with Mild Intellectual Disability: A Multiple Case Study. Behaviour Change, 25, 97-108. https://doi.org/10.1375/bech.25.2.97

Barisnikov, K., Van der Linden, M., \& Detraux, J.-J. (2002). Cognition sociale, troubles du comportement social et émotionnel chez les personnes présentant une déficience mentale. In G. Petitpierre (Ed.), Enrichir les compétences (pp. 31-39). Lucerne: Edition SPC.

Barisnikov, K., Van der Linden, M., \& Hippolyte, L. (2004). Tâche de résolution sociale. Genève.

Bernard-Opitz, V., Sriram, N., \& Nakhoda-Sapuan, S. (2001). Enhancing Social Problem Solving in Children with Autism and Normal Children through Computer-Assisted Instruction. Journal of Autism and Developmental Disorders, 31, 377-384. https://doi.org/10.1023/A:1010660502130

Boot, F. H., Pel, J. J. M., Evenhuis, H. M., \& van der Steen, J. (2012). Factors Related to Impaired Visual Orienting Behavior in Children with Intellectual Disabilities. Research in Developmental Disabilities, 33, 1670-1676.

https://doi.org/10.1016/j.ridd.2012.04.007

Borella, E., Carretti, B., \& Lanfranchi, S. (2013). Inhibitory Mechanisms in Down Syndrome: Is There a Specific or General Deficit? Research in Developmental Disabilities, 34, 65-71. https://doi.org/10.1016/j.ridd.2012.07.017

Carretti, B., Belacchi, C., \& Cornoldi, C. (2010). Difficulties in Working Memory Updating in Individuals with Intellectual Disability. Journal of Intellectual Disability Research, 54, 337-345. https://doi.org/10.1111/j.1365-2788.2010.01267.x

Conte, E., Grazzani, I., \& Pepe, A. (2018). Social Cognition, Language, and Prosocial Behaviors: A Multitrait Mixed-Methods Study in Early Childhood. Early Education and Development, 29, 814-830. https://doi.org/10.1080/10409289.2018.1475820

Cote, D. L. (2011). Implementing a Problem-Solving Intervention with Students with Mild to Moderate Disabilities. Intervention in School and Clinic, 46, 259-265. https://doi.org/10.1177/1053451210395387

Crick, N. R., \& Dodge, K. A. (1994). A Review and Reformulation of Social Information-Processing Mechanisms in Children's Social Adjustment. Psychological Bulletin, 115, 74-101. https://doi.org/10.1037/0033-2909.115.1.74

Crites, S. A., \& Dunn, C. (2004). Teaching Social Problem Solving to Individuals with mental Retardation. Education and Training in Developmental Disabilities, 39, 301-309.

Danielsson, H., Henry, L., Messer, D., \& Rönnberg, J. (2012). Strengths and Weaknesses in Executive Functioning in Children with Intellectual Disability. Research in Developmental Disabilities, 33, 600-607. https://doi.org/10.1016/j.ridd.2011.11.004 
Dekker, M. C., Koot, H. M., van der Ende, J., \& Verhulst, F. C. (2002). Emotional and Behavioral Problems in Children and Adolescents with and without Intellectual Disability. Journal of Child Psychology and Psychiatry, 43, 1087-1098.

https://doi.org/10.1111/1469-7610.00235

Deneault, J., \& Ricard, M. (2013). Are Emotion and Mind Understanding Differently Linked to Young Children's Social Adjustment? Relationships between Behavioral Consequences of Emotions, False Belief, and SCBE. The Journal of Genetic Psychology, 174, 88-116. https://doi.org/10.1080/00221325.2011.642028

Denham, S. A., Blair, K. A., DeMulder, E., Levitas, J., Sawyer, K., Auerbach-Major, S., \& Queenan, P. (2003). Preschool Emotional Competence: Pathway to Social Competence? Child Development, 74, 238-256. https://doi.org/10.1111/1467-8624.00533

Dennis, M., Agostino, A., Roncadin, C., \& Levin, H. (2009). Theory of Mind Depends on Domain-General Executive Functions of Working Memory and Cognitive Inhibition in Children with Traumatic Brain Injury. Journal of Clinical Experimental Neuropsychology, 31, 835-847. https://doi.org/10.1080/13803390802572419

Dodge, K. A. (2014). A Social Information Processing Model of Social Competence in Children. In M. Pelmutter (Ed.), Cognitive Perspectives on Children's Social and Behavioral Development (pp. 77-126). New York: Psychology Press.

Domitrovich, C. E., Cortes, R. C., \& Greenberg, M. T. (2007). Improving Young Children's Social and Emotional Competence: A Randomized Trial of the Preschool "PATHS" Curriculum. The Journal of Primary Prevention, 28, 67-91. https://doi.org/10.1007/s10935-007-0081-0

Fernández-Sotos, P., Torio, I., Fernández-Caballero, A., Navarro, E., González, P., Dompablo, M., \& Rodriguez-Jimenez, R. (2019). Social Cognition Remediation Interventions: A Systematic Mapping Review. PLoS ONE, 14, e0218720. https://doi.org/10.1371/journal.pone.0218720

Flavell, J. H. (1986). The Development of Children's Knowledge about the Appearance-Reality Distinction. American Psychologist, 41, 418-425.

https://doi.org/10.1037/0003-066X.41.4.418

Flavell, J. H. (1999). Cognitive Development: Children's Knowledge about the Mind. Annual Review of Psychology, 50, 21-45. https://doi.org/10.1146/annurev.psych.50.1.21

Flavell, J. H., Everett, B. A., Croft, K., \& Flavell, E. R. (1981). Young Children's Knowledge about Visual Perception: Further Evidence for the Level 1-Level 2 Distinctions. Developmental Psychology, 17, 99-103. https://doi.org/10.1037/0012-1649.17.1.99

Happé, F., Cook, J. L., \& Bird, G. (2017). The Structure of Social Cognition: In(ter)dependence of Sociocognitive Processes. Annual Review of Psychology, 68, 243-267. https://doi.org/10.1146/annurev-psych-010416-044046

Hauser-Cram, P., \& Woodman, A. C. (2016). Trajectories of Internalizing and Externalizing Behavior Problems in Children with Developmental Disabilities. Journal of $A b$ normal Child Psychology, 44, 811-821. https://doi.org/10.1007/s10802-015-0055-2

Hippolyte, L., Iglesias, K., Van der Linden, M., \& Barisnikov, K. (2010). Social Reasoning skills in Adults with Down Syndrome: The Role of Language, Executive Functions and Socio-Emotional Behaviour. Journal of Intellectual Disability Research, 54, 714-726. https://doi.org/10.1111/j.1365-2788.2010.01299.x

Honoré, N., Houssa, M., Volckaert, A., Noël, M.-P., \& Nader-Grosbois, N. (Submitted). Executive Functions and Social Cognition Training in the Classrooms. Frontiers in Psychology.

Houssa, M., \& Nader-Grosbois, N. (2016). Experimental Study of Middle-Term Training in Social Cognition for Pre-Schoolers. Journal of Education and Training Studies, 4, 61-73. https://doi.org/10.11114/jets.v4i1.972 
Houssa, M., Jacobs, E., \& Nader-Grosbois, N. (2016). Impact of Short-Term Training in Social Cognition in Preschoolers with Externalizing Behavior. Journal of Education and Training Studies, 5, 110-123. https://doi.org/10.11114/jets.v5i1.2081

Houssa, M., Mazzone, S., \& Nader-Grosbois, N. (2014). Validation d'une version francophone de l'inventaire de la Théorie de l'Esprit (ToMI-vf). Revue Européenne de Psychologie Appliquée/European Review of Applied Psychology, 64, 169-179. https://doi.org/10.1016/j.erap.2014.02.002

Houssa, M., Nader-Grosbois, N., \& Jacobs, E. (2014). Experimental Study of Short-Term Training in Social Cognition in Pre-Schoolers. Journal of Education and Training Studies, 2, 139-154. https://doi.org/10.11114/jets.v2i1.181

Howlin, P., Baron-Cohen, S., \& Hadwin, J. (2011). Apprendre aux enfants autistes à comprendre la pensée des autres. Bruxelles: de Boeck.

Hughes, C., Soares-Boucaud, I., Hochmann, J., \& Frith, U. (1997). Social Behaviour in Pervasive Developmental Disorders: Effects of Informant, Group and "Theory-Of-Mind". European Child \& Adolescent Psychiatry, 6, 191-198.

Hutchins, T. L., Bonazinga, L. A., Prelock, P. A., \& Taylor, R. S. (2008). Beyond False Beliefs: The development and Psychometric Evaluation of the Perceptions of Children's Theory of Mind Measure-Experimental Version (PCToMM-E). Journal or Autism and Developmental Disorders, 38, 143-155. https://doi.org/10.1007/s10803-007-0377-1

Hutchins, T. L., Prelock, P. A., \& Bonazinga, L. (2012). Psychometric Evaluation of the Theory of Mind Inventory (ToMI): A Study of Typically Developing Children and Children with Autism Spectrum Disorder. Journal of Autism and Developmental Disorder, 42, 327-341. https://doi.org/10.1007/s10803-011-1244-7

Hutchins, T. L., Prelock, P. A., \& Chace, W. (2008). Test-Retest Reliability of a Theory of Mind Task Battery for Children with Autism Spectrum Disorders. Focus on Autism and other Developmental Disabilities, 23, 195-206. https://doi.org/10.1177/1088357608322998

Jacobs, E., \& Nader-Grosbois, N. (2018a). SIP Program for Children. UCLouvain. Louvain-La-Neuve.

Jacobs, E., \& Nader-Grosbois, N. (2018b). ToM Program for Children. UCLouvain. Louvain-La-Neuve.

Jacobs, E., \& Nader-Grosbois, N. (2020a). Affective and Cognitive Theory of Mind in Children with Intellectual Disabilities: How to Train Them to Foster Social Adjustment and Emotion Regulation? Journal of Education and Training Studies, 8, 80-97. https://doi.org/10.11114/jets.v8i4.4757

Jacobs, E., \& Nader-Grosbois, N. (2020b). Training Social Information Processing in Elementary School Children with Intellectual Disabilities: A Key to Support Their Emotion Regulation and Social Behaviors. Journal of Education and Training Studies, 8, 7-22. https://doi.org/10.11114/jets.v8i6.4840

Jacobs, E., Léonard, C., Nader-Grosbois, N., Houssa, M., \& Mazzone, S. (2016). Entrainer la cognition sociale auprès d'enfants présentant une déficience intellectuelle. Revue Francophone de la Déficience Intellectuelle, 27, 127-140. https://doi.org/10.7202/1043129ar

Jacobs, E., Mazzone, S., Simon, P., \& Nader-Grosbois, N. (2019a). The Unexpected Impact of Parental Emotional Socialization on Theory of Mind and Emotion Regulation: The Case of Children with Intellectual Disabilities. Psychology, 10, 1302-1332. https://doi.org/10.4236/psych.2019.109084

Jacobs, E., Mazzone, S., Simon, P., \& Nader-Grosbois, N. (2019b). The Unforeseen Influence of Parents' Socialization Behaviors on the Social Adjustment of Children with Intellectual Disabilities Psychology, 10, 1275-1301. https://doi.org/10.4236/psych.2019.109083 
Jacobs, E., Simon, P., \& Nader-Grosbois, N. (2020). Social Cognition in Children with Non-Specific Intellectual Disability: An Exploratory Study. Frontiers in Psychology, 11, 1884. https://doi.org/10.3389/fpsyg.2020.01884

Kloo, D., \& Perner, J. (2003). Training Transfer between Card Sorting and False Belief Understanding: Helping Children Apply Conflicting Descriptions. Child Development, 74, 1823-1839. https://doi.org/10.1046/j.1467-8624.2003.00640.x

Lachavanne, A., \& Barisnikov, K. (2013). Rééducation des compétences socio-émotionnelles pour des adultes présentant une déficience intellectuelle. Revue Européenne de Psychologie Appliquée/European Review of Applied Psychology, 63, 345-352. https://doi.org/10.1016/j.erap.2013.09.002

Lanfranchi, S., Jerman, O., Dal Pont, E., Alberti, A., \& Vianello, R. (2010). Executive Function in Adolescents with Down Syndrome. Journal of Intellectual Disability Research, 54, 308-319. https://doi.org/10.1111/j.1365-2788.2010.01262.x

Lecce, S., \& Bianco, F. (2018). Working Memory Predicts Changes in Children's Theory of Mind during Middle Childhood: A Training Study. Cognitive Development, 47, 71-81. https://doi.org/10.1016/j.cogdev.2018.04.002

Leffert, J. S., \& Siperstein, G. N. (1996). Assessment of Social-Cognitive Processes in Children with Mental Retardation. American Journal on Mental Retardation, 100, 441-455.

Lemerise, E. A., \& Arsenio, W. F. (2000). An Integrated Model of Emotion Processes and Cognition in Social Information Processing. Child Development, 71, 107-118. https://doi.org/10.1111/1467-8624.00124

Lemerise, E. A., Gregory, D. S., \& Fredstrom, B. K. (2005). The Influence of Provocateurs' Emotion Displays on the Social Information Processing of Children Varying in Social Adjustment and Age. Journal of Experimental Child Psychology, 90, 344-366. https://doi.org/10.1016/j.jecp.2004.12.003

Li, X., Wang, K., Wu, J., Hong, Y., Zhao, J., Feng, X., \& Zhang, X. (2014). The Link between Impaired Theory of Mind and Executive Function in Children with Cerebral Palsy. Research in Developmental Disabilities, 35, 1686-1693.

https://doi.org/10.1016/j.ridd.2014.03.017

Mazza, M., Mariano, M., Peretti, S., Masedu, F., Pino, M. C., \& Valenti, M. (2017). The Role of Theory of Mind on Social Information Processing in Children with Autism Spectrum Disorders: A Mediation Analysis. Journal of Autism and Developmental Disorders, 47, 1369-1379. https://doi.org/10.1007/s10803-017-3069-5

Montoya-Rodríguez, M. M., \& Molina-Cobos, F. (2019). Training Perspective Taking Skills in Individuals with Intellectual Disabilities: A Functional Approach. Journal of Contextual Behavioral Science, 14, 1-10. https://doi.org/10.1016/j.jcbs.2019.08.003

Nader-Grosbois, N., \& Houssa, M. (2016). La Batterie de tâches de Théorie de l'esprit: Validation de la version francophone. Enfance, 2, 141-166. https://doi.org/10.4074/S0013754516002019

Nestler, J., \& Goldbeck, L. (2011). A Pilot Study of Social Competence Group Training for Adolescents with Borderline Intellectual Functioning and Emotional and Behavioural Problems (SCT-ABI). Journal of Intellectual Disability Research, 55, 231-241. https://doi.org/10.1111/j.1365-2788.2010.01369.x

O’Reilly, J., \& Peterson, C. C. (2014). Theory of Mind at Home: Linking Authoritative and Authoritarian Parenting Styles to Children's Social Understanding. Early Child Development and Care, 184, 1934-1947. https://doi.org/10.1080/03004430.2014.894034

O’Reilly, M. F., Lancioni, G. E., Sigafoos, J., O’Donoghue, D., Lacey, C., \& Edrisinha, C. 
(2004). Teaching Social Skills to adults with Intellectual Disabilities: A Comparison of External Control and Problem-Solving Interventions. Research in Developmental Disabilities, 25, 399-412. https://doi.org/10.1016/j.ridd.2003.07.003

Oswald, D. P., \& Ollendick, T. H. (1989). Role Taking and Social Competence in Autism and Mental Retardation. Journal of Autism and Developmental Disorders, 19, 119-127. https://doi.org/10.1007/BF02212723

Pears, K. C., \& Moses, L. J. (2003). Demographics, Parenting, and Theory of Mind in Preschool Children. Social Development, 12, 1-20.

https://doi.org/10.1111/1467-9507.00219

Perner, J., Lang, B., \& Kloo, D. (2002). Theory of Mind and Self-Control: More than a Common Problem of Inhibition. Child Development, 73, 752-767.

https://doi.org/10.1111/1467-8624.00436

Perner, J., Leekam, H., \& Wimmer, H. (1987). Three-Year-Olds' Difficulty with False Belief: The Case for a Conceptual Deficit. British Journal of Developmental Psychology, 5, 125-137. https://doi.org/10.1111/j.2044-835X.1987.tb01048.x

Radley, K. C., Ford, W. B., Battaglia, A. A., \& McHugh, M. B. (2014). The Effects of a Social Skills Training Package on Social Engagement of Children with Autism Spectrum Disorders in a Generalized Recess Setting. Focus on Autism and other Developmental Disabilities, 29, 216-229. https://doi.org/10.1177/1088357614525660

Raver, C. C. (2002). Emotions Matter: Making the Case for the Role of Young Children's Emotional Development for Early School Readiness. Social Policy Report, 16, 1-20. https://doi.org/10.1002/j.2379-3988.2002.tb00041.x

Rodas, N. V., Chavira, D. A., \& Baker, B. L. (2017). Emotion Socialization and Internalizing Behavior Problems in Diverse Youth: A Bidirectional Relationship across Childhood. Research in Developmental Disabilities, 62, 15-25.

https://doi.org/10.1016/j.ridd.2017.01.010

Rodas, N. V., Zeedyk, S. M., \& Baker, B. L. (2016). Unsupportive Parenting and Internalising Behaviour Problems in Children with or without Intellectual Disability. Journal of Intellectual Disability Research, 60, 1200-1211. https://doi.org/10.1111/jir.12332

Schalock, R. L., Borthwick-Duffy, S. A., Bradley, V. J., Buntinx, W. H., Coulter, D. L., Craig, E. M., \& Reeve, A. (2010). Intellectual Disability: Definition, Classification, and Systems of Supports (11th ed.). Washington, D.C.: American Association on Intellectual and Developmental Disabilities.

Shure, M. B. (1993). I Can Problem Solve (ICPS): Interpersonal Cognitive Problem Solving for Young Children. Early Child Development and Care, 96, 49-64. https://doi.org/10.1080/0300443930960106

Stewart, C. A., \& Singh, N. N. (1995). Enhancing the Recognition and Production of Facial Expressions of Emotion by Children with Mental Retardation. Research in Developmental Disabilities, 16, 365-382. https://doi.org/10.1016/0891-4222(95)00024-H

Thirion-Marissiaux, A.-F., \& Nader-Grosbois, N. (2008a). Theory of Mind "Beliefs", Developmental Characteristics and Social Understanding in Children and Adolescents with Intellectual Disabilities. Research in Developmental Disabilities, 29, 547-566. https://doi.org/10.1016/j.ridd.2007.09.004

Thirion-Marissiaux, A.-F., \& Nader-Grosbois, N. (2008b). Theory of Mind "Emotion", Developmental Characteristics and Social Understanding in Children and Adolescents with Intellectual Disabilities. Research in Developmental Disabilities, 29, 414-430. https://doi.org/10.1016/j.ridd.2007.07.001 
Thirion-Marissiaux, A.-F., \& Nader-Grosbois, N. (2008c). Theory of Mind and Socio-Affective Abilities in Disabled Children and Adolescents. European Journal of Disability Research, 2, 133-155. https://doi.org/10.1016/j.alter.2008.02.003

Valiente, C., Swanson, J., DeLay, D., Fraser, A. M., \& Parker, J. H. (2020). Emotion-Related Socialization in the Classroom: Considering the Roles of Teachers, Peers, and the Classroom Context. Developmental Psychology, 56, 578-594.

https://doi.org/10.1037/dev0000863

van Nieuwenhuijzen, M., \& Vriens, A. (2012). (Social) Cognitive Skills and Social Information Processing in Children with Mild to Borderline Intellectual Disabilities. Research in Developmental Disabilities, 33, 426-434. https://doi.org/10.1016/j.ridd.2011.09.025

van Nieuwenhuijzen, M., Orobio De Castro, B., Van der Valk, I., Wijnroks, L., Vermeer, A., \& Matthys, W. (2006). Do Social Information-Processing Models Explain Aggressive Behaviour by Children with Mild Intellectual Disabilities in Residential Care? Journal of Intellectual Disability Research, 50, 801-812. https://doi.org/10.1111/j.1365-2788.2005.00773.x

van Nieuwenhuijzen, M., Orobio de Castro, B., Wijnroks, L., Vermeer, A., \& Matthys, W. (2004). The Relations between Intellectual Disabilities, Social Information Processing, and Behaviour Problems. European Journal of Developmental Psychology, 1, 215-229. https://doi.org/10.1080/17405620444000111

van Nieuwenhuijzen, M., Orobio de Castro, B., Wijnroks, L., Vermeer, A., \& Matthys, W. (2009). Social Problem-Solving and Mild Intellectual Disabilities: Relations with Externalizing Behavior and Therapeutic Context. American Journal on Intellectual and Developmental Disabilities, 114, 42-51. https://doi.org/10.1352/2009.114:42-51

Van Rest, M. M., Matthys, W., Van Nieuwenhuijzen, M., De Moor, M. H., Vriens, A., \& Schuengel, C. (2018). Social Information Processing Skills Link Executive Functions to Aggression in Adolescents with Mild to Borderline Intellectual Disability. Child Neuropsychology, 25, 573-598. https://doi.org/10.1080/09297049.2018.1495186

Visu-Petra, L., Benga, O., Incaş, I., \& Miclea, M. (2007). Visual-Spatial Processing in Children and Adolescents with Down's Syndrome: A Computerized Assessment of Memory Skills. Journal of Intellectual Disability Research, 51, 942-952. https://doi.org/10.1111/j.1365-2788.2007.01002.x

Vlachou, A., \& Stavroussi, P. (2016). Promoting Social Inclusion: A Structured Intervention for Enhancing Interpersonal Problem-Solving Skills in Children with Mild Intellectual Disabilities. Support for Learning, 31, 27-45. https://doi.org/10.1111/1467-9604.12112

Webster-Stratton, C., \& Hammond, M. (1997). Treating Children with Early-Onset Conduct Problems: A Comparison of Child and Parent Training Interventions. Journal of Consulting and Clinical Psychology, 65, 93-109. https://doi.org/10.1037/0022-006X.65.1.93

Wechsler, D. (2004). Echelle d'intelligence de Wechsler pour la période préscolaire et primaire (Vol. 3). Paris: Paris Les éditions du Centre de Psychologie appliquée.

Wimmer, H., \& Perner, J. (1983). Beliefs about Beliefs: Representation and Constraining Function of Wrong Beliefs in Young children's Understanding of Deception. Cognition, 13, 103-128. https://doi.org/10.1016/0010-0277(83)90004-5

Yeates, K. O., Bigler, E. D., Dennis, M., Gerhardt, C. A., Rubin, K. H., Stancin, T., \& Vannatta, K. (2007). Social Outcomes in Childhood Brain Disorder: A Heuristic Integration of Social Neuroscience and Developmental Psychology. Psychological Bulletin, 133, 535-556. https://doi.org/10.1037/0033-2909.133.3.535 


\section{Appendix A. Table Describing Timing and Objectives Used in} ToM and SIP Programs for Children

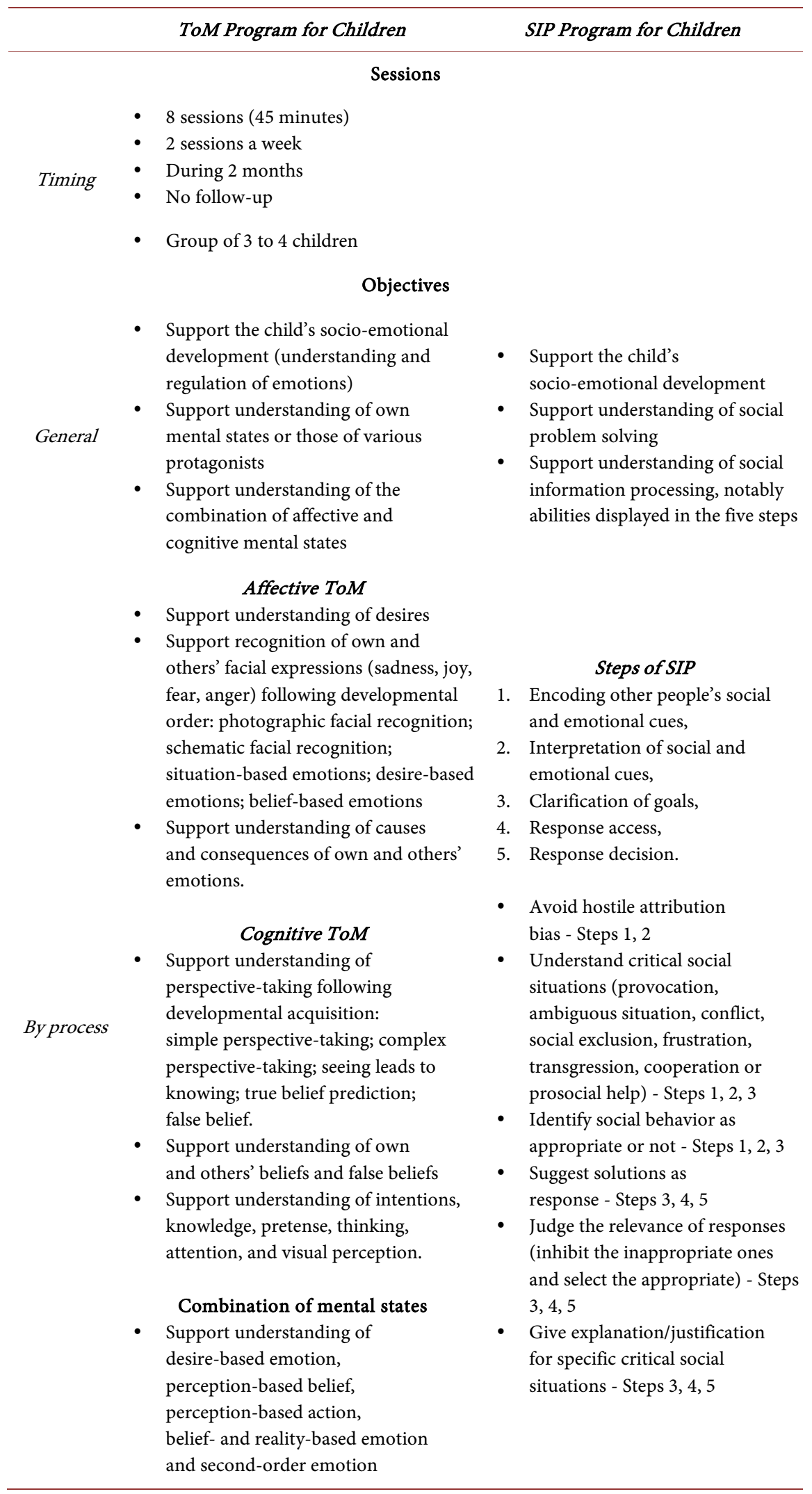




\section{Continued}

\begin{tabular}{|c|c|c|}
\hline By session & How do I feel? & Is this situation good or bad? \\
\hline 1 & Affective ToM & Steps 1,2 \\
\hline 2 & $\begin{array}{l}\text { What do I believe? } \\
\text { Cognitive ToM }\end{array}$ & $\begin{array}{l}\text { How can I judge if it is good or bad? } \\
\text { Steps } 1,2\end{array}$ \\
\hline 3 & $\begin{array}{l}\text { Why do I have this feeling? (I)? } \\
\text { Affective ToM }\end{array}$ & $\begin{array}{l}\text { What should I do in these situations? } \\
\text { Steps } 3,4,5\end{array}$ \\
\hline 4 & $\begin{array}{l}\text { Why do I have this feeling? (II)? } \\
\text { Affective ToM }\end{array}$ & $\begin{array}{l}\text { Are there other possible responses? } \\
\text { Steps } 3,4,5\end{array}$ \\
\hline 5 & $\begin{array}{l}\text { My beliefs and me (I) } \\
\text { Cognitive ToM }\end{array}$ & $\begin{array}{l}\text { How should I deal with critical } \\
\text { social situations? } \\
\text { Steps } 3,4,5\end{array}$ \\
\hline 6 & $\begin{array}{l}\text { How to react afterwards } \\
\text { Affective ToM }\end{array}$ & $\begin{array}{l}\text { How should I deal with critical } \\
\text { social situations? } \\
\text { Steps } 3,4,5\end{array}$ \\
\hline 7 & $\begin{array}{l}\text { My beliefs and me (II) } \\
\text { Cognitive ToM }\end{array}$ & $\begin{array}{l}\text { How should I deal with social } \\
\text { situations? } \\
\text { Steps } 1,2,3,4,5\end{array}$ \\
\hline $\begin{array}{c}8 \\
\text { Integrative } \\
\text { session }\end{array}$ & $\begin{array}{l}\text { Booster and integrative session } \\
\text { Combination of mental states }\end{array}$ & $\begin{array}{l}\text { Booster and integrative session } \\
\text { Steps } 1,2,3,4,5\end{array}$ \\
\hline
\end{tabular}

\section{Appendix B. Table Describing Material Used in ToM and SIP Programs for Children}

\begin{tabular}{|c|c|c|}
\hline & ToM Program for Children & SIP Program for Children \\
\hline \multicolumn{3}{|c|}{ Material } \\
\hline Support & $\begin{array}{l}\text { Games (Puzzles, Feelings, Mental } \\
\text { Simil, Guess why...); Pretend play; } \\
\text { Images; Extracts of cartoons; Picture } \\
\text { books eliciting affective and or } \\
\text { cognitive mental states }\end{array}$ & $\begin{array}{l}\text { Games (Problems, Card Boxes...); } \\
\text { Images; Videos; Picture books } \\
\text { illustrating positive and negative } \\
\text { social situations similar to what } \\
\text { children have experienced }\end{array}$ \\
\hline & $\begin{array}{l}\text { Visual support for key concept } \\
\text { Visual support for emotions }\end{array}$ & Visual support for key questions \\
\hline $\begin{array}{l}\text { Eliciting } \\
\text { Situations }\end{array}$ & $\begin{array}{l}\text { Situations inducing affective and } \\
\text { cognitive ToM, as well as the } \\
\text { combination of mental states }\end{array}$ & $\begin{array}{l}\text { Critical or ambiguous social situations } \\
\text { inducing the five steps of SIP }\end{array}$ \\
\hline $\begin{array}{c}\text { By Session } \\
1\end{array}$ & $\begin{array}{l}\text { Affective ToM: Expression and } \\
\text { Causes of Emotions }\end{array}$ & $\begin{array}{l}\text { Provocation (3); } \\
\text { Conflict (4); } \\
\text { Social Exclusion (6); } \\
\text { Transgression (2); } \\
\text { Prosocial (6) }\end{array}$ \\
\hline 2 & $\begin{array}{l}\text { Cognitive ToM: Perspective-taking; } \\
\text { Belief-False belief; Attention; } \\
\text { Intentions; Knowledge }\end{array}$ & $\begin{array}{l}\text { Provocation (2); } \\
\text { Conflict; Social Exclusion (2); } \\
\text { Ambiguous Situation (1); } \\
\text { Cooperation (1); } \\
\text { Prosocial (1) }\end{array}$ \\
\hline
\end{tabular}




\section{Continued}

4

Affective ToM: Expression,

Causes and Consequences of Emotions

Cognitive ToM: Perspective-Taking;

5

6

Affective ToM: Causes and

Consequences of Emotions

Affective ToM: Causes of Emotions and Desire

Cognitive ToM: Perspective-Taking; Visual perception; Belief-False belief Intentions; Knowledge; Attention; Pretense

8

Integrative session
Provocation (2);

Conflict (2);

Social Exclusion (2);

Transgression (6);

Ambiguous Situation (1);

Cooperation (3);

Prosocial (2)

Provocation (6);

Conflict (1);

Social Exclusion (5);

Cooperation (3);

Prosocial (1)

Provocation (4);

Conflict (4);

Social Exclusion (3)

Ambiguous Situation (2);

Frustration (3);

Prosocial (2)

Provocation (4);

Conflict (1);

Social Exclusion (3);

Frustration (2)

Provocation (2);

Conflict (2);

Social Exclusion (1);

Transgression (1)

+ Game-Emotional

Thermometer (Child chooses from different critical social situations and matches the situation with a solution.)

Provocation (1);

Conflict (1);

Transgression (3);

Cooperation (2);

\section{Appendix C. Table Describing Techniques Used in ToM and SIP Programs for Children}

\begin{tabular}{|c|c|}
\hline & ToM Program for Children \\
\hline & Techniques-Questions \\
\hline $\begin{array}{c}\text { Similar } \\
\text { techniques }\end{array}$ & $\begin{array}{l}\text { - Repetition } \\
\text { - Asking for justification or explanation by children for each of their } \\
\text { responses } \\
\text { - Immediate and differentiated feedback as reinforcer or correction, } \\
\text { provided after each response } \\
\text { - Explanation by the experimenter of the correct response } \\
\text { - } \text { right answers } \\
\text { - Conversations and use of terms relating to eliciting situations } \\
\text { - Connections with real life events }\end{array}$ \\
\hline
\end{tabular}




\section{Continued}

Differentiated techniques or questions
- Conversations and use of terms relating to mental states

- Discussions arising from questions about mental states

- Semi-open key questions on Affective ToM:

- "How does he feel?"

"Why does he feel that way?"

"What will he do?"

- Semi-open questions on Cognitive ToM:

- "What does he believe?"

"What is it really?"

"What does it look like?"

\section{Related to Affective ToM}

- Identification of desires

- Identification of emotions

- Identification of causes of emotions

- Identification of consequences of emotions

- Judgment about emotional reaction Identification of appropriate reaction to emotional situations

Related to Cognitive ToM

- Denomination of deceptive objects and experimenter's demonstration of the distinction between appearance and reality

- Role-play inducing change of location games or deception

- Demonstration of mirror pictures

- Identification of beliefs and false beliefs

Related to Mixed ToM:

- Identification of the difference between desires, intentions and beliefs

- Identification of consequences of several mental states
- Conversations and use of terms relating to critical social situations

- Discussions arising from questions about critical social situations

- Semi-open questions about critical social situations

- What happened? Is it good or bad? - Step 1

- Was it done on purpose or was it an accident? - Step 2

- What would you do in such a situation? - Step 3

- Why is it good or bad? Could he do/say something else? - Step 4

- Is this solution a good response? - Step 5

- Identification of social and emotional cues - Steps 1, 2

- Identification of alternative solutions to critical social situations - Steps 3, 4

- Selection and activation of the best solution in relation to critical social situations - Steps 3, 4, 5

- Justification of each response by increasing complexity level (descriptive, intersubjective and conceptual) 